\author{
Chemical Technology Division
}

\title{
Wastewater Triad Project: Solid-Liquid Separator FY 2000 Deployment
}

\author{
J. F. Walker, Jr. \\ T. E. Kent
}

Date Published: November 2000

\author{
Prepared for ORO-8-SD-10 \\ Milestone C-1
}

\author{
Prepared by the \\ OAK RIDGE NATIONAL LABORATORY \\ Oak Ridge, Tennessee 37831-6285 \\ managed by \\ UT-BATTELLE, LLC \\ for the \\ U.S. DEPARTMENT OF ENERGY \\ under contract DE-AC05-00OR22725
}





\section{CONTENTS}

Page

LIST OF TABLES AND FIGURES $\ldots \ldots \ldots \ldots \ldots \ldots \ldots \ldots \ldots \ldots \ldots \ldots \ldots \ldots \ldots$

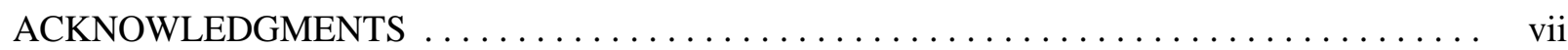

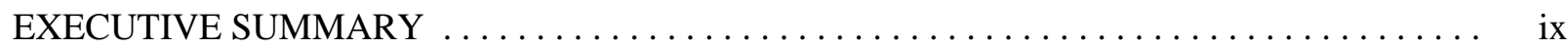

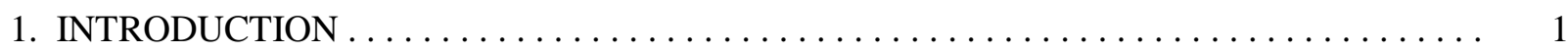

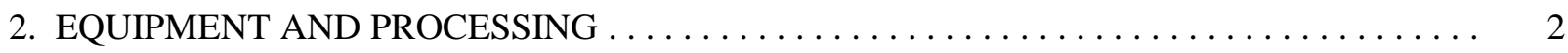

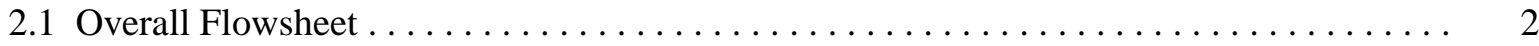

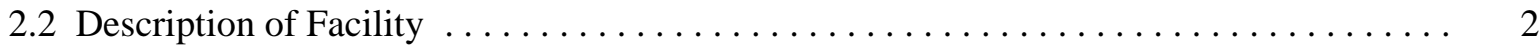

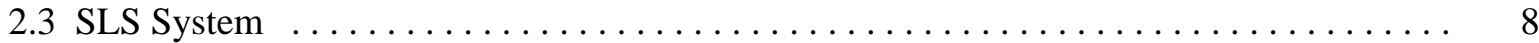

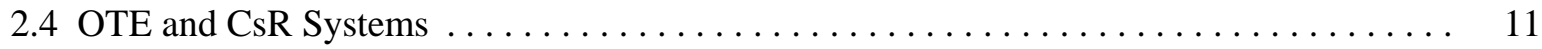

3. PROCEDURES AND FUNCTIONAL TESTING $\ldots \ldots \ldots \ldots \ldots \ldots \ldots \ldots \ldots \ldots \ldots \ldots$

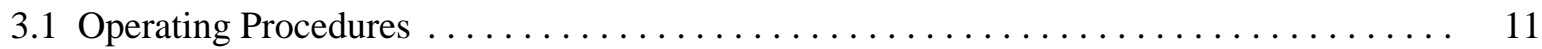

3.2 Functional Testing and Readiness Assessment for the SLS System . . . . . . . . . 12

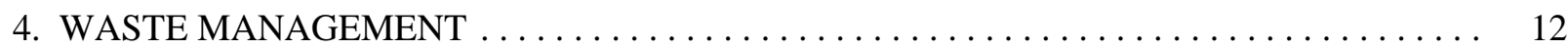

5. AS LOW AS REASONABLY ACHIEVABLE (ALARA) GOALS $\ldots \ldots \ldots \ldots \ldots \ldots \ldots$

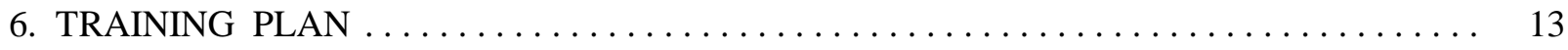

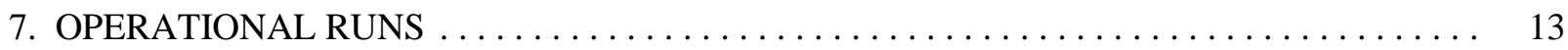

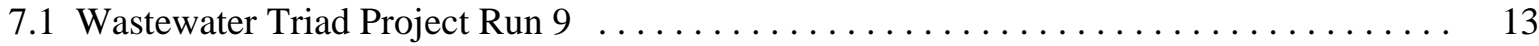

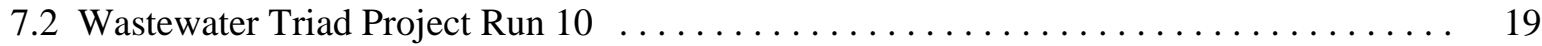

7.3 Evaluation of the Dual Coriolis Meter System $\ldots \ldots \ldots \ldots \ldots \ldots \ldots \ldots \ldots \ldots$

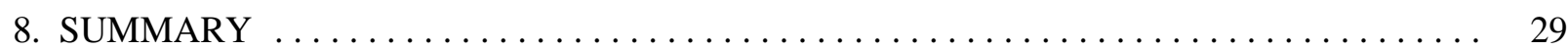

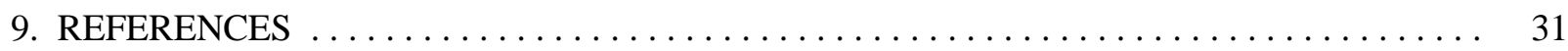





\section{LIST OF TABLES AND FIGURES}

Page

Table 1

Summary of WTP processing runs to date

14

Figure $1 \quad$ Schematic diagram of WTP operating systems $\ldots \ldots \ldots \ldots \ldots \ldots \ldots \ldots$

Figure 2 Flow options for the WTP operations where supernate is treated and transferred to CIP tanks . . . . . . . . . . . . . . . . . . . 4

Figure 3 Flow options for the WTP operations where supernate from the CIP tanks is treated and transferred to the MVSTs $\ldots \ldots \ldots \ldots \ldots \ldots \ldots$

Figure $4 \quad$ Aerial view of Melton Valley Storage Tank facility $\ldots \ldots \ldots \ldots \ldots \ldots \ldots$

Figure $5 \quad$ Flowsheet of the SLS feed system, filtration loop, and chemical feed system ... 9

Figure $6 \quad$ Isometric drawing of the solid-liquid separator $\ldots \ldots \ldots \ldots \ldots \ldots \ldots$

Figure $7 \quad$ Solids content of SLS feed as a function of time for Run $9 \ldots \ldots \ldots \ldots$

Figure $8 \quad$ Filtrate flow rate as a function of time for Run $9 \ldots \ldots \ldots \ldots \ldots \ldots \ldots$

Figure $9 \quad$ Feed flow rate to the SLS system as a function of time for Run $9 \ldots \ldots \ldots$

Figure $10 \quad$ Axial flow rate across the filter elements as a function of time for Run $9 \ldots \ldots 20$

Figure $11 \quad$ Transmembrane pressure as a function of time for Run $9 \ldots \ldots \ldots \ldots \ldots \ldots$

Figure $12 \quad$ Solids content of feed as a function of time for Run $10 \ldots \ldots \ldots \ldots \ldots \ldots$

Figure $13 \quad$ Flow rate of feed to the SLS system as a function of time for Run $10 \ldots \ldots 23$

Figure $14 \quad$ Axial flow rate across filter elements as a function of time for Run $10 \ldots \ldots 24$

Figure $15 \quad$ Filtrate flow rate as a function of time for Run $10 \ldots \ldots \ldots \ldots \ldots \ldots$

Figure $16 \quad$ Transmembrane pressure as a function of time for Run $10 \ldots \ldots \ldots \ldots \ldots \ldots$

Figure $17 \quad$ Pressure drop across the filters as a function of time for Run $10 \ldots \ldots \ldots \ldots$ 



\section{ACKNOWLEDGMENTS}

The successful completion of this project was made possible through a dedicated team effort involving many individuals and organizations over the span of several years. The U.S. Department of Energy (DOE) Tank Focus Area (TFA) was the major provider of funding for the project and made possible the integration of technical support from several different DOE sites where state-of-the-art filtration technologies were being developed and evaluated. The TFA recognized that the support of this project would benefit environmental management activities at Oak Ridge and across the DOE complex by providing local processing capability and evaluating the performance of a full-scale solid/liquid separation (SLS) system for potential application in tank waste pretreatment at other DOE sites. The program contributions of C. S. Mims and J. N. Dial, of DOE-Oak Ridge Operations (DOE-ORO), were vital to the project. Their vision of the SLS system as an integral part of the remediation activity associated with the Bethel Valley Watershed was critical. S. M. Robinson and C. P. McGinnis, of the ORNL Chemical Technology Division, have provided dedicated support through their coordination of the project with TFA, DOE-ORO, and Waste Operations since the inception of the project in 1996. V. L. Fowler and J. D. Hewitt performed the early filtration tests with tank waste samples, which indicated that cross-flow filtration (the selected technology for the SLS system) could be used successfully. D. J. McCabe and R. A. Peterson, of the Savannah River Technology Center, provided excellent technical support and generated important test data with simulated wastes during the early test phases of the program. J. H. Wilson and A. J. Lucero, of the ORNL Chemical Technology Division, led the follow-on effort involving filtration tests using several waste samples from both the Melton Valley Storage Tanks and the gunite tanks. J. H. Wilson and J. R. Farmer, of the ORNL Engineering Division, led the development of design specifications for the system and selected NUMET Engineering, Ltd., as the design and fabrication subcontractor for the full-scale SLS system. J. R. Farmer and R. D. Gray, Quality Engineering, performed thorough quality assurance inspections during fabrication of the SLS system by NUMET. C. McMeekin and the design/fabrication team at NUMET provided a well-designed, high-quality, and well-documented SLS system that performed in nearly flawless fashion. Bechtel Jacobs Company, LLC, Waste Operations Project team under the management of C. E. Frye and C. B. Scott provided excellent field operations and maintenance support for the project. The field operations shift leaders from the Radiochemical Technology Section, of the ORNL Chemical Technology Division, provided outstanding, dedicated support of the operation. This team included R. L. Cummins, B. S. Evans, L. L. Farr, J. D. Hewitt, H. L. Jennings, S. A. Richardson, P. A. Taylor, and J. F. Walker. 
Installation and evaluation of the dual Coriolis meter system for monitoring on line suspended solids concentrations were provided by T. D. Hylton, of the Radiochemical Technology Section of the ORNL Chemical Technology Division. 


\section{EXECUTIVE SUMMARY}

The Wastewater Triad Project (WTP) consists of three operational units: the cesium removal system (CsR), the out-of-tank evaporator (OTE) system, and the solid/liquid separation (SLS) system. These systems were designed to reduce the volume and radioactivity of LLLW stored in the MVSTs and can be operated independently or in series in order to accomplish the treatment goals. Each of these is a modular, skid-mounted system that is self-contained, individually shielded, and designed to be decontaminated and removed once the project has been completed. The CsR and OTE systems are installed inside Building 7877; the SLS system is installed adjacent to the east side of the MVST 7830 vault cover. The objective of this report is to provide a summary of the operations for the SLS system during the deployment phase in FY 2000. Operational information on the OTE and CsR systems is to be provided in a report to be issued at a later date.

Five runs were completed during FY 2000. Two of these (i.e., Runs 9 and 10) included the SLS system. Run 9 began on March 10 and was completed on March 28, 2000. Approximately 12,000 gal of waste was processed through the SLS during this run. The solids content initially started at $\sim 2 \mathrm{wt} \%$ and rapidly decreased to $<1 \mathrm{wt} \%$. After the cone had been stabilized, the solids content in the feed remained below $1 \mathrm{wt} \%$ for $\sim 16$ days of operation. On March 27, however, it started to rise, increasing from $\sim 0.6 \mathrm{wt} \%$ to $\sim 3 \mathrm{wt} \%$ over a period of approximately $28 \mathrm{~h}$. It then jumped from $\sim 3 \mathrm{wt} \%$ to $\sim 22 \mathrm{wt} \%$, indicating that the cone around the suction leg in MVST W-24 had collapsed. During the early portion of Run 9, the filtrate production rate increased to $\sim 4-5 \mathrm{gal} / \mathrm{min}$ and operated at this level for $\sim 8$ days before declining to the rate of $\sim 1 \mathrm{gal} / \mathrm{min}$, where it stayed for the remainder of the run ( $\sim 2$ days $)$. The 4-5-gal/min rate was typical of that observed during the latter stage of the SLS demonstration, which occurred earlier in FY 2000 prior to Run 9. The filtrate production rate for a cross-flow filter typically declines for a short period after startup and then reaches a steady-state production rate. The $\sim 1$-gal/min rate reached at the close of Run 9 was adequate for the WTP because the CsR and OTE systems generally operate at $1 \mathrm{gal} / \mathrm{min}$; therefore, the SLS did not become a bottleneck for the downstream processes.

Run 10 was initiated on March 29 and completed on April 15, with 13,000 gal of supernate being processed through the SLS system. During Run 10, 72 h of operation was required to stabilize the cone in MVST W-26 after the cone had been formed. During this 72-h period, the solids content of the feed to the SLS decreased from $\sim 10 \mathrm{wt} \%$ to $\sim 0.6 \mathrm{wt} \%$. The solids content of the feed remained below $\sim 1 \mathrm{wt} \%$ for $\sim 4$ days; then the cone began to break up, introducing more solids into the SLS feed. 
On April 10, the cone again seemed to stabilize and the solids content increased from $\sim 1 \mathrm{wt} \%$ to $\sim 9 \mathrm{wt} \%$ over a period of 5 days. When the solids content reached $>9 \mathrm{wt} \%$, the feed to the SLS was shut off, the solids were rinsed from the system, and Run 10 was terminated. The feed flow rate to the SLS and the axial flow rate across the filters during Run 10 were very similar to those in Run 9, with the feed flow rate being erratic and the axial flow rate running steady (except for step changes in the axial flow made by the operator to examine the effects on the filtrate production rate). The filtrate production rate was generally in the range of $\sim 1-2 \mathrm{gal} / \mathrm{min}$ during Run 10 . This filtrate production rate was typical of the rate observed at the end of Run 9, indicating that filtrate production may have reached a steady-state level for this system. Again, the $\sim 1$-gal/min rate did not become a bottleneck for the downstream processes because the OTE and CsR systems were designed to operate at $\sim 1 \mathrm{gal} / \mathrm{min}$.

During WTP Runs 9 and 10, two Coriolis meters were used simultaneously to create a suspended solids monitoring system that would provide accurate results with high precision. One Coriolis meter was used to measure the density of the slurry, while the other meter was used to measure the density of the carrier fluid (i.e., the filtrate from the cross-flow filter elements after the solids had been removed). The suspended solids concentration was then calculated from the density relationships between the slurry, the carrier fluid, and the dry solid particles. The density of the dry solids was determined by laboratory analysis and was assumed to be constant throughout the periods that grab samples were collected. Grab samples were collected and analyzed to verify the results obtained with the dual Coriolis meter system. The results showed that the concentrations of suspended solids as reported by this system tended to be slightly higher than those obtained from laboratory results. The standard deviation of the suspended solids concentration determined with the dual instruments was $0.08 \%$. The precision (or repeatability) for the Coriolis meters was very good; each meter had a standard deviation of $\leq 0.0005$ $\mathrm{g} / \mathrm{mL}$ for the density. These results are quite satisfactory when one considers that the densities of the slurries were 0.01 to $0.05 \mathrm{~g} / \mathrm{mL}$ greater than those of the filtrates. 


\section{INTRODUCTION}

The Wastewater Triad Project (WTP) consists of three operational units: the cesium removal (CsR) system, the out-of-tank evaporator (OTE) system, and the solid/liquid separation (SLS) system. These systems were designed to reduce the volume and radioactivity of low-level liquid waste (LLLW) stored in the Melton Valley Storage Tanks (MVSTs) and are operated independently or in series in order to accomplish the treatment goals. Each is a modular, skid-mounted system that is self-contained, individually shielded, and designed to be decontaminated and removed once the project has been completed. The CsR and OTE systems are installed inside Building 7877; the SLS system is installed adjacent to the east side of the MVST 7830 vault cover. The CsR, which consists of ion-exchange equipment for removing ${ }^{137} \mathrm{Cs}$ from LLLW, was demonstrated in 1997. During the Cesium Removal Demonstration, 30,853 gal of radioactive supernate was processed and $1142 \mathrm{Ci}$ of ${ }^{137} \mathrm{Cs}$ was removed from the supernate and loaded onto 70 gal of a crystalline silicotitanate sorbent manufactured by UOP, Inc. The OTE system is a subatmospheric single-stage evaporator system designed to concentrate LLLW to smaller volumes. It was previously demonstrated in 1996 and was operated in 1998 to process about 80,000 gal of LLLW. The SLS system was designed to filter and remove suspended solids from LLLW in order to minimize further accumulation of sludge in new storage tanks or to prevent fouling of CsR and OTE systems. The SLS was installed and demonstrated in 1999; 45,000 gal of radioactive supernate was processed during the demonstration.

Details of the demonstration of the OTE, CsR, and SLS systems have been published previously. ${ }^{1-3}$ Following the demonstrations of the three individual treatment systems, each of them was modified and upgraded so that it could be operated individually or in series. The three systems were then collectively deployed in baseline operations at ORNL as the Wastewater Triad Project (WTP). The earlier demonstrations of the individual systems (i.e., the OTE, the CsR, and the SLS) were designed to collect the detailed data and information necessary to upgrade the systems and to place them in baseline operations. During the deployment phase in FY 1999 and FY 2000, the WTP was part of ORNL's Integrated Tank Waste Management Plan, which combined the accelerated deployment of innovative technologies with an aggressive waste transfer schedule to meet the State of Tennessee Commissioner's unilateral order that requires treatment of transuranic sludge to begin by June 2002. During the deployment phase, data collection was limited to that information required to comply with operational or environmental permits and requirements. Therefore, the level of detail available for these systems during the demonstration phase is not available for the deployment phase. 
The objective of this report is to provide a summary of the operations for the SLS system during the deployment phase in FY 2000. Operational information on the OTE and CsR systems will be published in a report to be issued at a later date.

\section{EQUIPMENT AND PROCESSING}

\subsection{Overall Flowsheet}

The general layout/flowsheet of the WTP system is provided in Fig. 1. In the treatment process, LLLW from any one of the eight MVSTs (W-24 through W-31) is first pumped through the SLS system for filtration. The filtrate is promptly sent to the CsR system feed tank (capacity, 500 gal), from which it is pumped through ion-exchange columns to remove ${ }^{137} \mathrm{Cs}$ and is then routed to the OTE system feed tank, which holds about 350 gal. The OTE system heats and evaporates water from the liquid and transfers the concentrated LLLW to the Capacity Increase Project (CIP) tanks for storage. The evaporated water is condensed, cooled, collected in a transport tank, and finally routed to the ORNL Process Waste System for treatment and discharge to the environment. The ion-exchange sorbent (manufactured by UOP LLC and designated as IONSIVTM IE-911), which traps the ${ }^{137} \mathrm{Cs}$, is removed from the ion-exchange column, dewatered, and packaged for on-site storage as solid low-level waste. The IONSIV ${ }^{\text {TM }}$ IE-911 is processed and packaged to meet the Nevada Test Site (NTS) Waste Acceptance Criteria and will be shipped to NTS for disposal at a later date. Most of the valving and control for the WTP systems is automated and operated from a control room situated in Building 7863, approximately $75 \mathrm{ft}$ away from Buildings 7877 and 7830. Remote video cameras are utilized to view different aspects of the process. Optional processing schemes also include (1) use of the existing 7830 decant system instead of the SLS system for providing LLLW to the CsR and OTE systems, (2) independent operation of the CsR or the OTE using either the decant system or the SLS system to provide LLLW feed, (3) independent operation of the SLS system to filter LLLW for recycle to or for storage in the CIP tanks, (4) operation of the OTE feed tank as a booster station for transferring LLLW from the MVSTs to the CIP tanks, and (5) receipt of LLLW from the CIP tanks to perform CsR and/or OTE processing. Box diagrams illustrating these treatment options are provided in Figs. 2 and 3.

\subsection{Description of Facility}

All waste processed by the SLS system was pumped from the MVST facility. This facility consists of eight 50,000-gal stainless steel horizontal tanks, each about $60 \mathrm{ft}$ long and $12 \mathrm{ft}$ in diameter. 


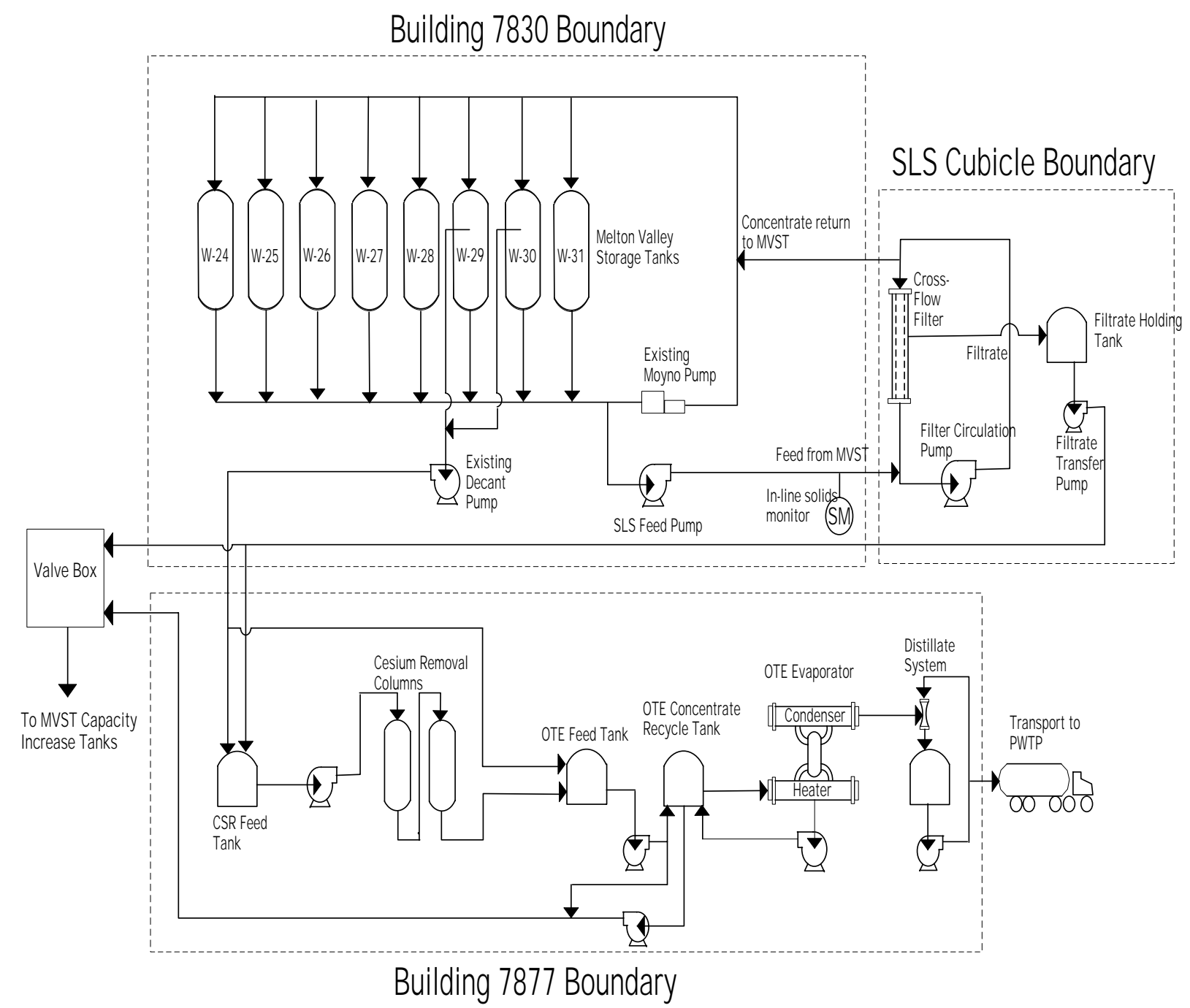

Fig. 1. Schematic diagram of WTP operating systems. 


\section{MVST to CIP Flow Options}
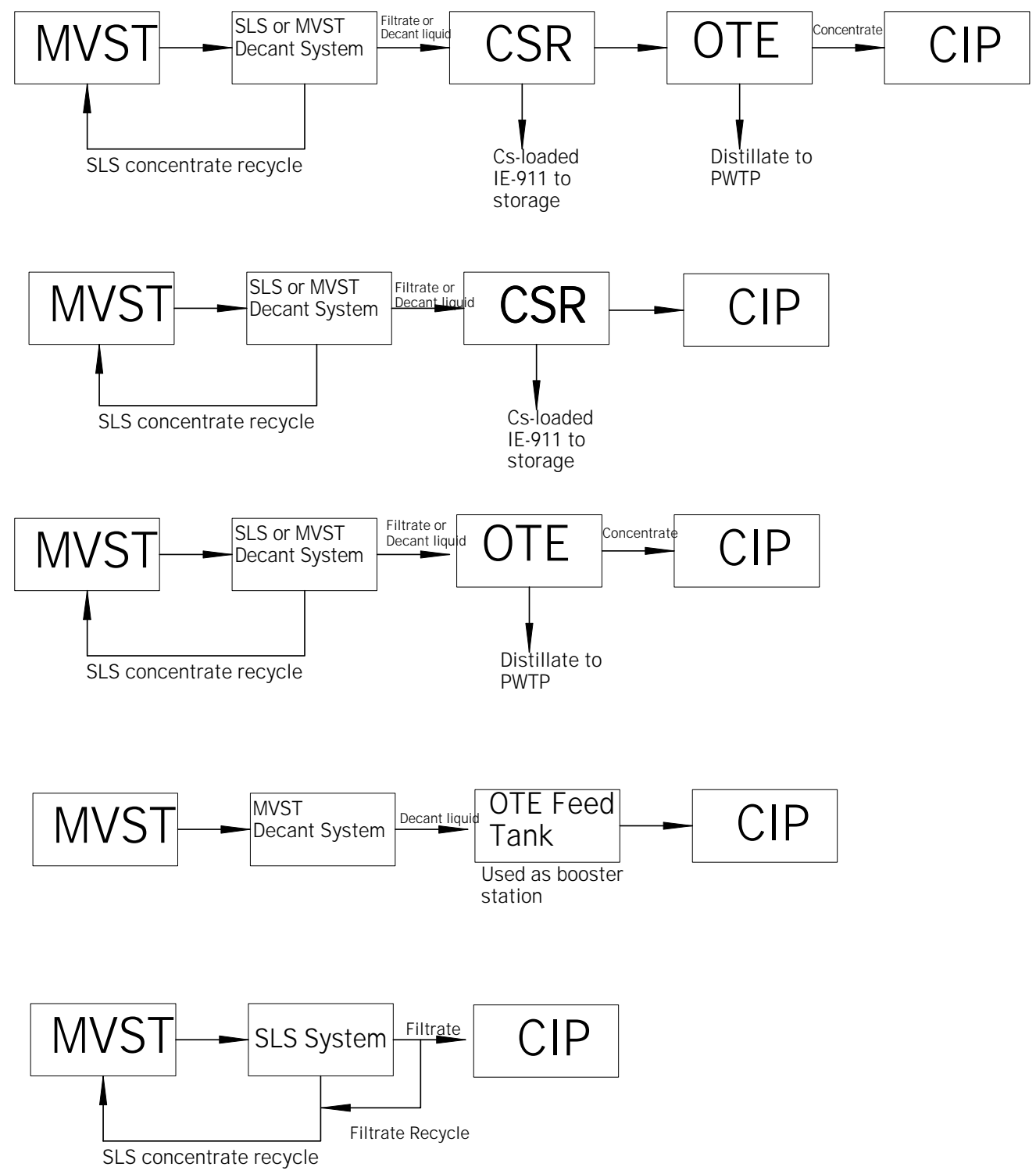

Fig. 2. Flow options for the WPT operations where supernate is treated and transferred to CIP tanks. 


\section{CIP to MVST Flow Options}
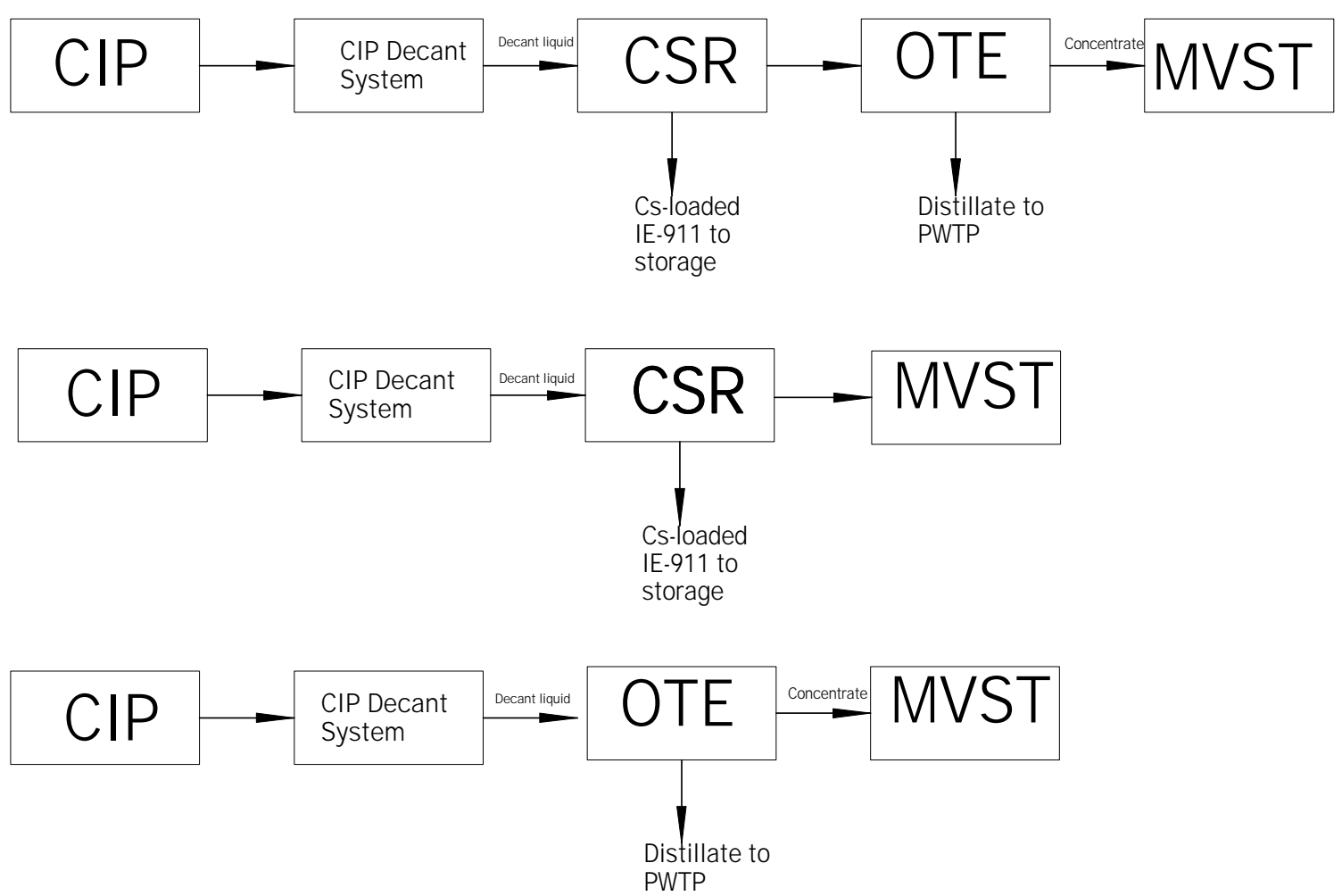

Fig. 3. Flow options for the WTP operations where supernate from the CIP tanks is treated and transferred to the MVSTs. 
The tanks were built within an underground concrete vault containing a stainless steel liner for spill containment. The walls and ceiling of the vault provide containment and radiation shielding. The vault also includes a pump-and-valve vault (PVV), where piping is routed from the tank feed lines, drain lines, sample lines, and other connections. The waste transfer piping for the tanks is routed within the PVV to two large progressive-cavity pumps designed for cross-site and intertank transfers. The vault also includes a HEPA-filtered ventilation system for control of airborne contamination. An aboveground control room (Building 7830) housing the tank level instrumentation, ventilation system controls, and pump controls is located adjacent to the south side of the vault. A photograph of the MVST facility is shown in Fig. 4.

In the early 1980s, it became apparent that a supernate treatment system was needed to create additional storage capacity in the MVSTs. A facility (Building 7877) designed to allow grouting of the supernate for disposal was constructed adjacent to the 7830 control room. To provide clarified supernate feed to the grout facility, a supernate decant system was added to the MVSTs. The decant system included the installation of dip-leg piping into tanks W-29 and W-30 to allow decanting of about one-half of the working volume of each tank. The dip legs were piped to a shielded double-diaphragm pump located within a containment structure on top of the vault. The discharge piping of the pump was routed within a shielded pipe chase along the top of the vault into Building 7877. The grouting materials and equipment were provided through a subcontract to a private service company specializing in mobile radwaste grouting services. This facility is currently being used to provide containment for the OTE and CsR systems.

Design of the piping, electrical, and structural interfaces between the SLS system and the MVST facility was provided by ORNL Engineering. This involved evaluation of several plans for locating and piping the system and selecting the most practical and cost-effective option. It was decided to locate the SLS system on a new foundation adjacent to the east end of the MVST tank vault and to install the feed pumps and interface piping within the existing PVV. The design for this option was reviewed by ORNL Safety Engineering to determine its impact on the facility-safety basis and associated documentation for the MVST facility (Building 7830), which is a Class II nuclear facility. Several design modifications were made to the interface systems to improve containment and to reduce the risk to personnel and the environment from the potential consequences of tornadoes, earthquakes, and other accident scenarios. In addition, several facility-safety documents required revisions to incorporate the SLS operation. New processes, such as the SLS system, that involve modifications of a Class II facility cannot be started until the affected safety documents have been approved. These revisions required several months to 


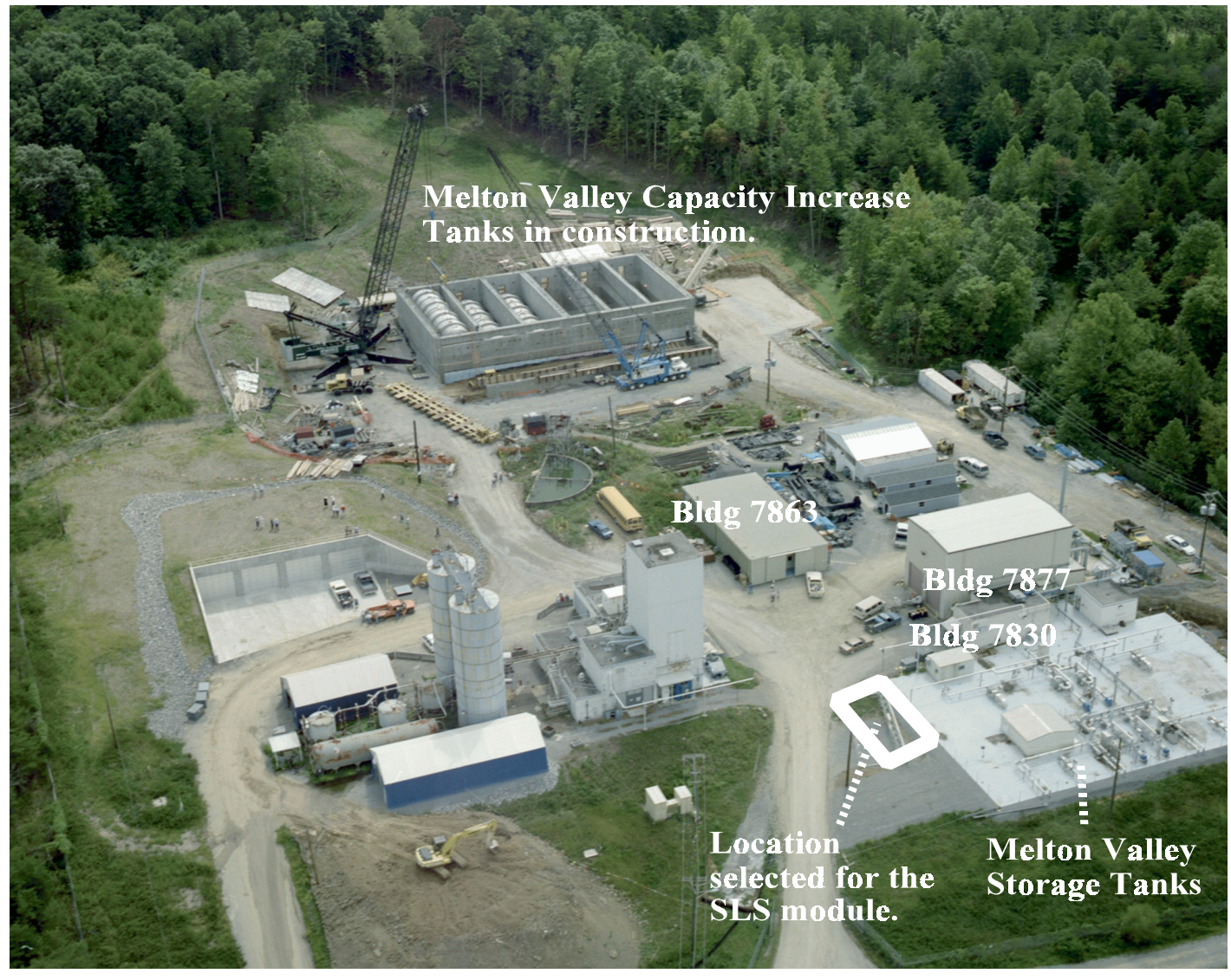

Fig. 4. Aerial view of Melton Valley Storage Tank facility. 
implement and involved careful preparation, ORNL site review and approval, and DOE-ORO review and approval. For the SLS system, revisions of the Building 7830 Operational Safety Requirements and the Building 7856 Technical Safety Requirements were required. In addition, two Unresolved Safety Question Determination documents had to be prepared prior to installation and operation of the SLS system.

\subsection{SLS System}

Detailed design information on the SLS system, which was designed and constructed by NUMET Engineering, Ltd., has been published previously. ${ }^{3}$ The SLS system consists of (1) a waste feed system that is located inside the MVST PVV and (2) a skid-mounted module that includes a cross-flow filter system, a chemical feed system, and shielding — all installed within a secondary containment pan and ventilated enclosure. The SLS system has been designed so that it can be used to process supernatant from any of the eight underground MVSTs. A schematic diagram of the SLS feed system, filtration loop, and chemical feed system is presented in Fig. 5; an isometric drawing of the SLS is shown in Fig. 6. The feed system consists of Moyno pumps, which were present in the MVST underground vaults prior to installation of the SLS and were used to transfer waste between tanks, and two double-diaphragm pumps, which were installed as part of the SLS system. The filtration loop consists of two cross-flow filter modules connected in series, a circulation pump, a backpulse system for backflushing the filters, a filtrate holding tank, and a filtrate transfer pump. The chemical cleaning system consists of two chemical addition tanks. The filter modules consist of two 5-ft-long bundles (containing 31 tubes per bundle) of 0.75 -in.-ID tubes, each having a nominal pore size of $0.5 \mu \mathrm{m}$. The total filter surface area is $50 \mathrm{ft}^{2}$. The tubes are contained within a shell having a diameter of about 9 in.; the assembly is similar to that of a shell-and-tube heat exchanger.

Prior to processing the MVST supernatant, the MVST transfer Moyno pumps were operated in a recycle mode to fill the piping and to create a depression, or cone, in the sludge layer of the MVST. Once the cone had been established and the piping was full, the Moyno pump was turned off and the double-diaphragm feed pumps were energized to provide flow to the filtration flow loop at the rate of 30 to $50 \mathrm{gpm}$. The feed entered the filtration loop at the suction area of the filter circulation pump, which typically operates at flow rates ranging from 200 to $500 \mathrm{gal} / \mathrm{min}$. The circulation pumps acted to provide an axial flow across the surface of the filters sufficient to prevent solids from accumulating on the surface and thereby inhibiting the transfer of filtrate through the $0.5-\mu \mathrm{m}$ filter pores. The filter circulation pump moved the supernatant through the tube side of the two filter modules and returned a 
SLS MODULE

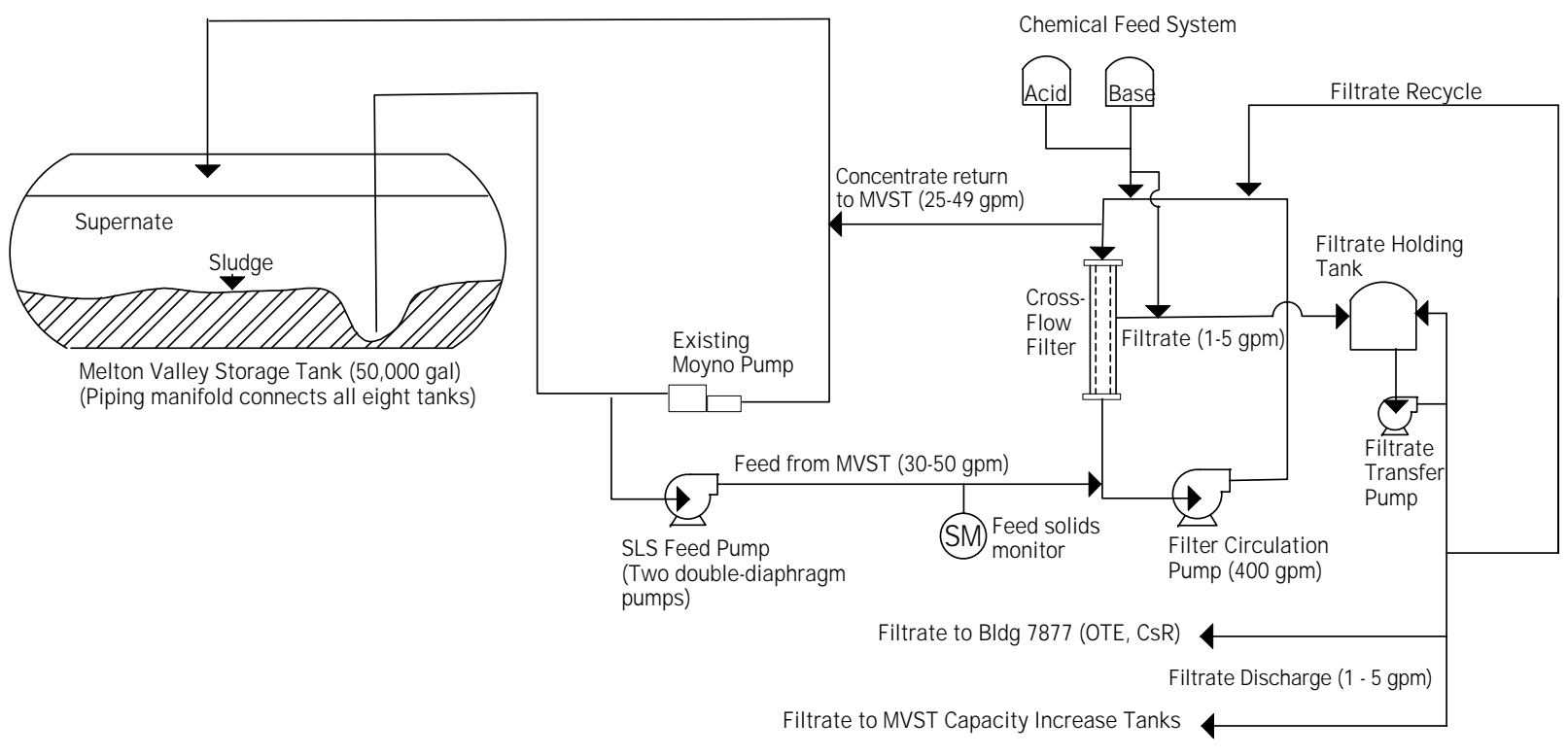

Fig. 5. Flowsheet of the SLS feed system, filtration loop, and chemical feed system. 


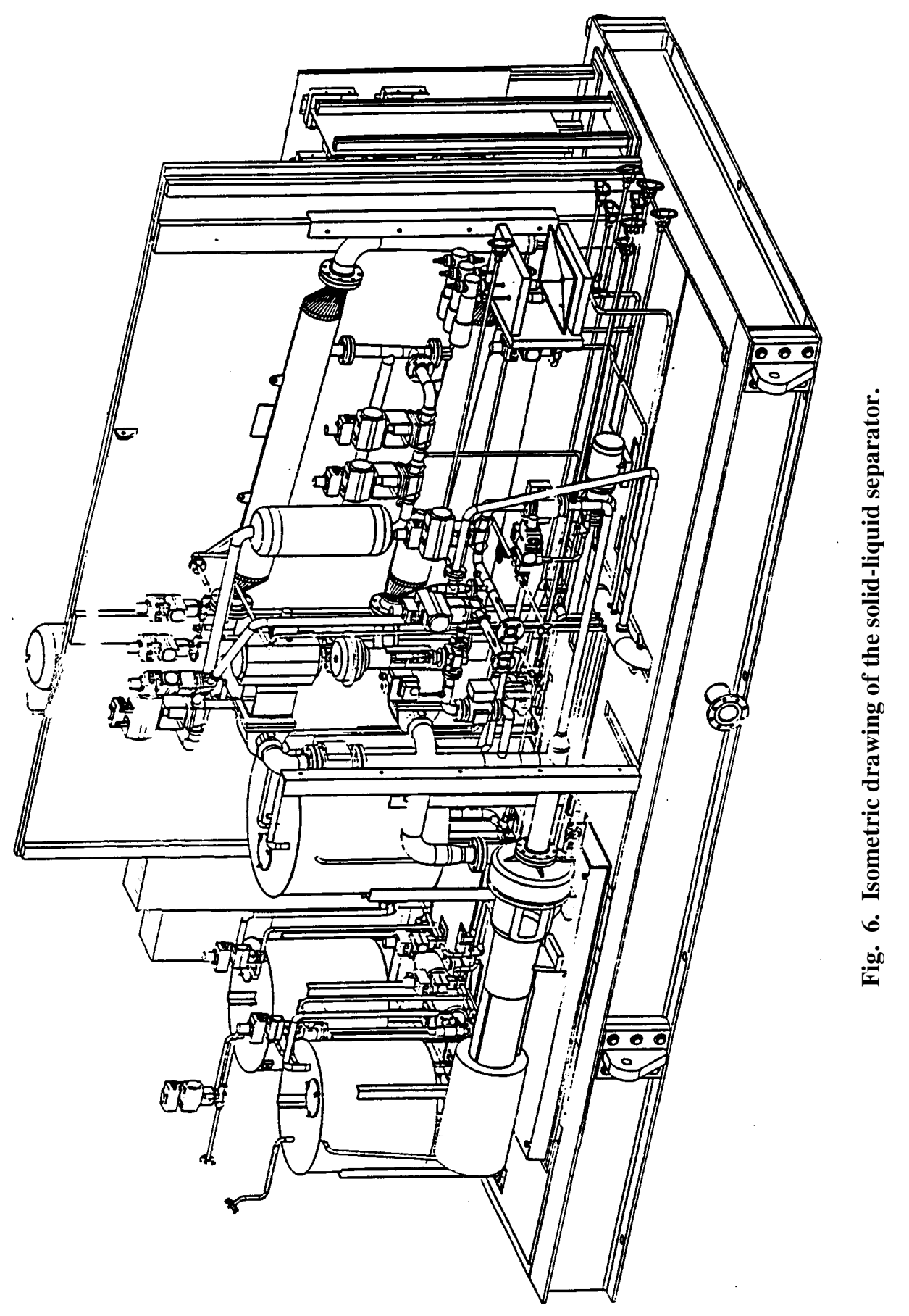


more concentrated liquid to the MVST from which the feed was taken. The tube side of the flow loop was pressurized up to $40 \mathrm{psig}$ by the double-diaphragm pump to force the liquid through the filter elements and into the shell side of the filter module. The SLS system is designed for a filtrate flow rate ranging from about 1 to $5 \mathrm{gpm}$. The filtrate is collected in a 120-gal holding tank and transferred, for recycle processing, to one of three locations: (1) the MVST CIP tanks (Building 7856), (2) the OTE or the CsR system, or (3) the MVST from which the feed was transferred. The filtrate flow rate will vary as a function of the pressure on the tube side, the liquid velocity through the tubes, the concentration of suspended solids in the liquid, and the degree of fouling of the filter elements. The backpulse system is designed to minimize fouling of the filter elements by applying a pressurized (100-psig) pulse of fluid in the reverse direction of the filtrate flow, which pushes the solids away from the tube wall and into the flow stream-thus flushing them out of the tube. If fouling of the filter elements is more severe, chemical cleaning can be performed using dilute nitric acid. Most of the valving and controls are automated and operated from a control room in Building 7863, which is located approximately $75 \mathrm{ft}$ away from the filter module. Remote video cameras are installed within the SLS cubicle to view the system during operation.

\subsection{OTE and CsR Systems}

Detailed design information on the OTE and CsR systems can be found in previous publications. ${ }^{1,2}$ These systems will not be discussed here because a report to be prepared in FY 2001 will document all operations for the OTE and CsR systems on dilute supernate waste processing that occurred during FY 2000.

\section{PROCEDURES AND FUNCTIONAL TESTING}

\subsection{Operating Procedures}

Formal operating procedures were prepared for the WTP operating systems and can be referred to for details. ${ }^{4}$ These procedures are controlled documents and will be revised to reflect any changes necessary for improved operations in accordance with the RTS Document Control Procedure. ${ }^{5}$ The verification documentation for the procedures is located in the Radiochemical Technology Section Document Management Center (RTS DMC). 


\subsection{Functional Testing and Readiness Assessment for the SLS System}

During FY 1999, an SLS demonstration run was conducted in which 42,000 gal of supernate was processed. The SLS control system had been connected to the CsR and OTE control systems prior to this demonstration. No major system upgrades to the SLS system were necessary before operation was begun in FY 2000; however, a Coriolis meter was initially installed in the SLS system to continually monitor the density of the filtrate and to improve the measurement of the suspended solids concentration. In addition, the SLS system was functionally tested along with the CsR and OTE systems. This testing included verification that (1) all valves were functioning properly, (2) all major equipment items were operating properly, (3) no liquid leaks were occurring at system operational pressures, (4) all operational procedures had been tested and were in place, (5) system interlocks and system safety controls were operating properly, and (6) the controls for the SLS, CsR, and OTE systems were functioning satisfactorily while operating individually or in series.

A Readiness Assessment, which is required by DOE orders, involves documentation that equipment and personnel are ready and that management controls are in place for the start of hot operations. There are different levels of rigor for these assessments, depending on the potential safety, environment, facility, and cost impacts of the operation. Based on the characteristics of this project, a Readiness Self-Assessment was recommended and accepted by DOE-ORO. The equivalent of this task for BJC LGWOP was an Internal Field Evaluation (IFE). Since BJC had recently become responsible for the operation of all waste systems at ORNL, DOE-ORO worked closely with BJC to ensure that the IFE was sufficiently rigorous and satisfied the intent of a complete self-assessment. DOE provided a Readiness Criteria list to BJC to use as a guide for the self-assessment. Details of the Readiness Assessment for the SLS have been published previously. ${ }^{3}$

\section{WASTE MANAGEMENT}

The primary waste streams from the WTP operations included (1) the LLLW supernate, (2) loaded sorbent from processing LLLW supernate, and (3) compactible LLLW from construction and shutdown operations. A Waste Management Plan was written and approved for the WTP; a record copy of this plan can be found in the RTS DMC. 


\section{AS LOW AS REASONABLY ACHIEVABLE (ALARA) GOALS}

Since each of the three systems in the WTP was designed and installed to process radioactive supernate, careful planning was necessary to meet ORNL's ALARA goals. A member of the ORNL Office of Radiation Protection worked with the project team to assess the WTP in terms of these goals. An ALARA plan was written for the WTP; a record copy of this plan can be found in the RTS DMC.

\section{TRAINING PLAN}

A training plan was prepared to ensure that all personnel involved in the testing and operation of the WTP systems have adequate training. A record copy of this plan, as well as the training records, can be found in the RTS DMC.

\section{OPERATIONAL RUNS}

Five operational runs were conducted during FY 2000. A summary of the processing information for these runs is presented in Table 1. Details of the CsR and OTE operations will be presented in a report to be written and published in FY 2001. Of the five runs completed in FY 2000, two (i.e., Runs 9 and 10) included the SLS system.

\subsection{Wastewater Triad Project Run 9}

WTP Run 9 processed the feed from MVST W-24 utilizing the SLS and OTE systems in series. This run began on March 10 and was completed on March 28, 2000. Approximately 12,000 gal of waste was processed through the SLS during the run. A graph showing the weight percent of undissolved solids in the SLS feed as a function of time is presented in Fig. 7. The concentration of solids initially started at $\sim 2 \mathrm{wt} \%$ and then rapidly decreased to $<1 \mathrm{wt} \%$. It is typical for the solids level in the SLS feed to be higher initially due to the design of the MVST facility. The suction legs for the SLS system are located near the bottom of the MVSTs, well below the level of the accumulated sludge in the tanks. To avoid transferring concentrated sludge to the SLS system, Moyno pumps, which are part of the MVST facility, are initially operated to reticulate the sludge in the tank and clear the sludge surrounding the suction leg. After the sludge has been cleared from the dip leg, the MOYNO are de-energize and the double-diaphragm pumps that feed the SLS system are energized. Several hours may be required for the 
Table 1. Summary of WTP processing runs to date

\begin{tabular}{|c|c|c|c|c|c|c|c|}
\hline Run & Process(es) & Start/end date & $\begin{array}{l}\text { Volume } \\
\text { processed } \\
\quad \text { (gal) }\end{array}$ & $\begin{array}{l}{ }^{137} \mathrm{Cs} \\
\text { removed } \\
(\mathrm{Ci})\end{array}$ & $\begin{array}{l}\text { Volume } \\
\text { evaporated } \\
\text { (gal) }\end{array}$ & $\begin{array}{c}\text { Inlet } \\
{ }^{137} \mathrm{Cs} \\
(\mathrm{mg} / \mathrm{L})\end{array}$ & $\begin{array}{c}\text { Inlet } \\
\text { nitrate } \\
(\mathrm{mg} / \mathrm{L})\end{array}$ \\
\hline 1 & CsR & 5-18-99/5-25-99 & 19,340 & 1,980 & $\mathrm{NA}^{\mathrm{a}}$ & $1.00 \mathrm{E}+06$ & 286,000 \\
\hline 2 & CsR, OTE & $5-26-99 / 6-4-99$ & 19,244 & 1,017 & 5,400 & $5.20 \mathrm{E}+05$ & 271,000 \\
\hline 3 & SLS, OTE, CsR & $6-7-99 / 6-24-99$ & 28,450 & 1,896 & 11,000 & $8.00 \mathrm{E}+05$ & 201,000 \\
\hline 4 & OTE & $6-25-99 / 7-15-99$ & 20,565 & NA & 9,800 & $4.60 \mathrm{E}+05$ & 150,000 \\
\hline 5 & SLS, OTE, CsR & 7-24-99/8-21-99 & 13,590 & 438 & 7,968 & $7.50 \mathrm{E}+05$ & 2,750 \\
\hline \multirow[t]{2}{*}{6} & CsR, OTE & 9-13-99/9-30-99 & 8,320 & 835 & 4,189 & $8.60 \mathrm{E}+05$ & 192,000 \\
\hline & FY1999 Totals & & 109,509 & 6,166 & 38,357 & & \\
\hline 6 (contd.) & CsR, OTE & $10-1-99 / 10-31-99$ & 12,107 & 961 & 4,823 & $8.60 \mathrm{E}+05$ & 192,000 \\
\hline 7 & CsR, OTE:OTE & $10-31-99 / 1-26-00$ & 21,202 & 89 & 8,991 & $1.90 \mathrm{E}+05$ & 37,000 \\
\hline 8 & CsR, OTE & $2-3-00 / 2-19-00$ & 17,277 & 495 & 10,034 & $2.80 \mathrm{E}+05$ & 54,900 \\
\hline 9 & SLS, OTE & $3-10-00 / 3-28-00$ & 11,911 & NA & 5,685 & $1.98 \mathrm{E}+05$ & 3,390 \\
\hline \multirow[t]{2}{*}{10} & SLS, OTE & $3-29-00 / 4-15-00$ & 13,357 & NA & 6,937 & $1.32 \mathrm{E}+05$ & 6,010 \\
\hline & FY 2000 totals & & 75,854 & 1,545 & 36,470 & & \\
\hline
\end{tabular}

${ }^{a} \mathrm{NA}=$ Not applicable. 


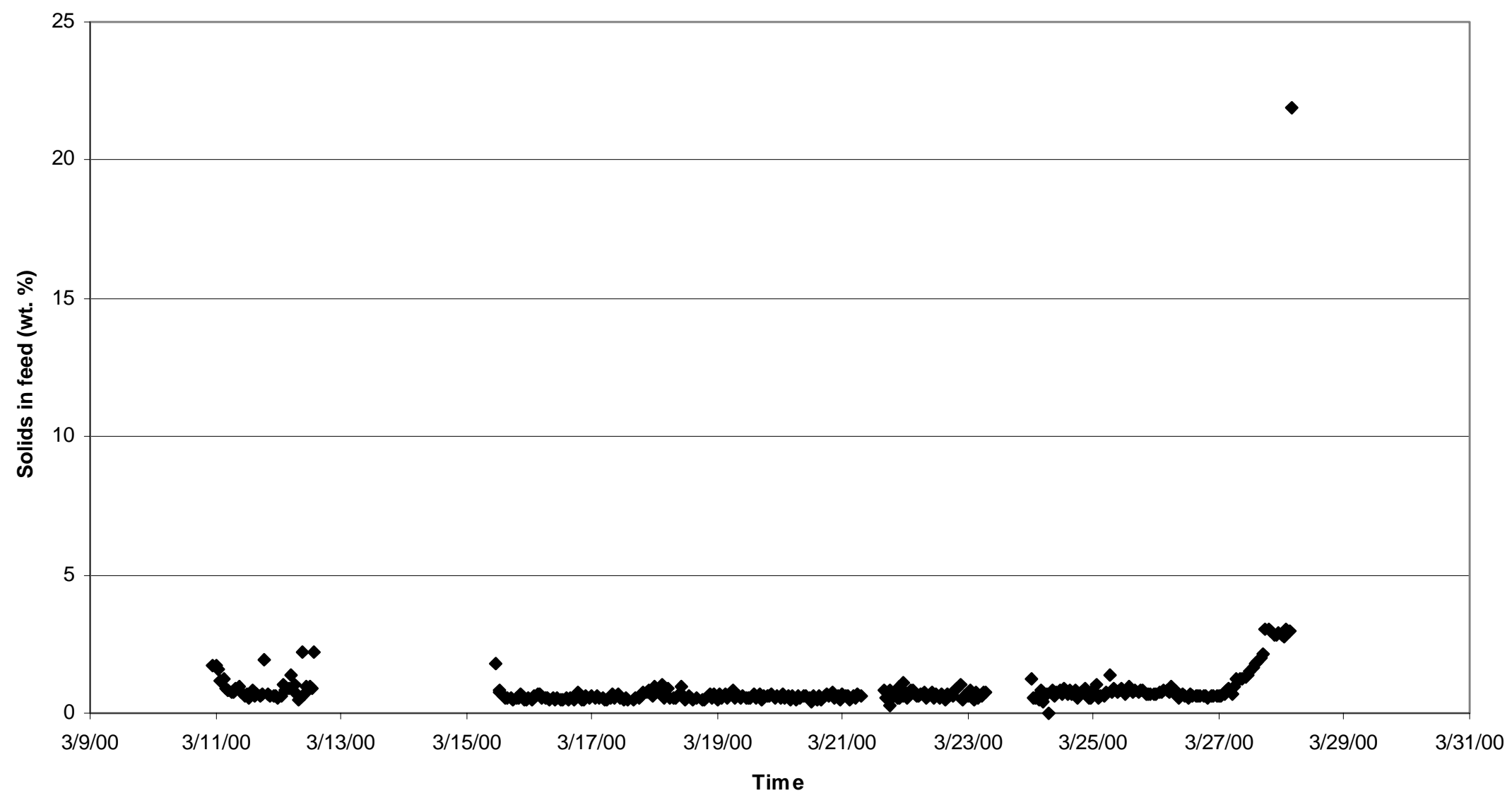

Fig. 7. Solids content of SLS feed as a function of time for Run 9. 
latter pumps to pick up the loose solids in the cone formed by the Moyno pumps and for the cone to stabilize. After the cone had been stabilized in WTP Run 9, the solids content remained below $1 \mathrm{wt} \%$ for $\sim 16$ days of operation. On March 27, however, the solids content in the feed started to rise, increasing from $\sim 0.6 \mathrm{wt} \%$ to $\sim 3 \mathrm{wt} \%$ over a period of approximately $28 \mathrm{~h}$. The solids content then jumped from $\sim 3 \mathrm{wt} \%$ to $\sim 22 \mathrm{wt} \%$, indicating that the cone had collapsed around the suction leg in the MVST being processed. The SLS system was subsequently flushed with water to remove any solids that were present. During the flushing operation, meetings were held with personnel responsible for waste operations at ORNL to assess the possibility of re-forming the cone in MVST W-24. Material balances indicated that the liquid level in MVST W-24 had dropped below the surface of the sludge layer in the tank and the cone could not be re-formed.

Figure 8 presents the filtrate flow rate as a function of time for Run 9. As shown in the Figure, this flow rate often dropped to zero. This decrease occurred because the filtrate was produced in 80-gal batches and the filtrate discharge valve would close when the high-level set point indicated that the filtrate tank was full. The SLS control system was programmed to send the filtrate to the CsR feed tank only when the CsR feed tank had enough capacity to accept the 80-gal batch. As can be seen from Fig. 8, the filtrate production rate increased to $\sim 4-5 \mathrm{gal} / \mathrm{min}$ and operated at this level for $\sim 8$ days before declining to $\sim 1 \mathrm{gal} / \mathrm{min}$ over the next 2 days. The $4-5$-gal/min rate was typical of that observed during the latter stage of the SLS demonstration conducted earlier in FY 2000. ${ }^{3}$ The filtrate production rate for a crossflow filter typically declines for a period after startup and then reaches steady state. The $\sim 1$-gal/min rate achieved at the close of Run 9 was adequate for the WTP because the CsR and OTE systems generally operate at $1 \mathrm{gal} / \mathrm{min}$; therefore, the SLS did not become a bottleneck for the downstream processes.

The feed flow rate to the SLS system as a function of time is presented in Fig. 9. The target flow rate to the SLS system was typically 30 to $50 \mathrm{gal} / \mathrm{min}$; however, the inlet flow was very erratic and was often above or below the target value. Some of this variability can be attributed to the pulsed flow from the double-diaphragm pumps that fed the SLS system. These pumps were used because the MVSTs are located in an underground vault and the SLS system is positioned above the tanks. The negative suction lift can be as high as $18 \mathrm{ft}$ if the liquid level in the tank is low. The double-diaphragm pumps were used because they are designed for a large suction lift and are self-priming. However, operational problems occurred with these pumps, possibly because of solids buildup in the piping to the pump suction. Backflushing of the double-diaphragm suction piping would temporarily increase the flow through these pumps. 


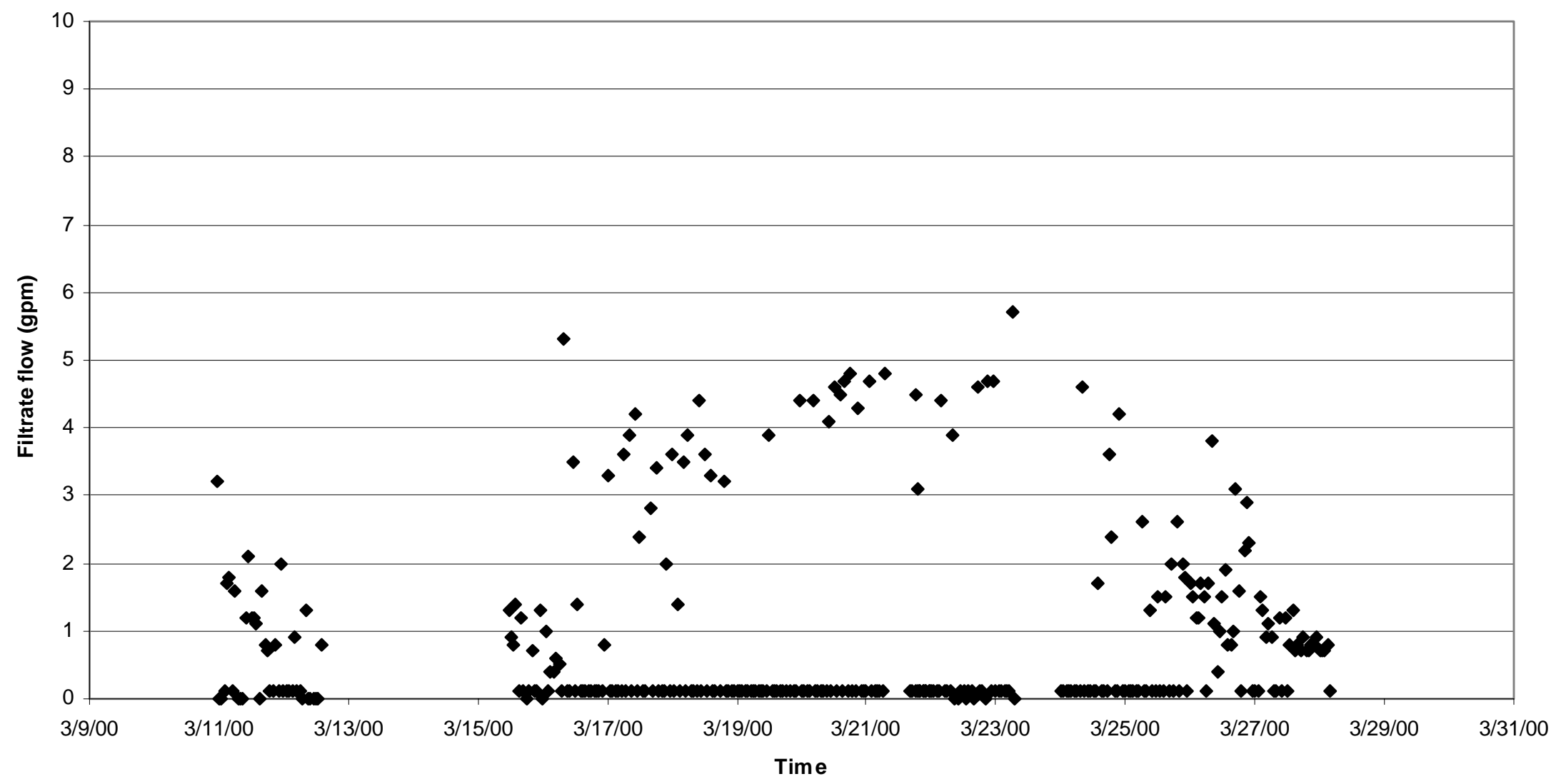

Fig. 8. Filtrate flow rate as a function of time for Run 9. 


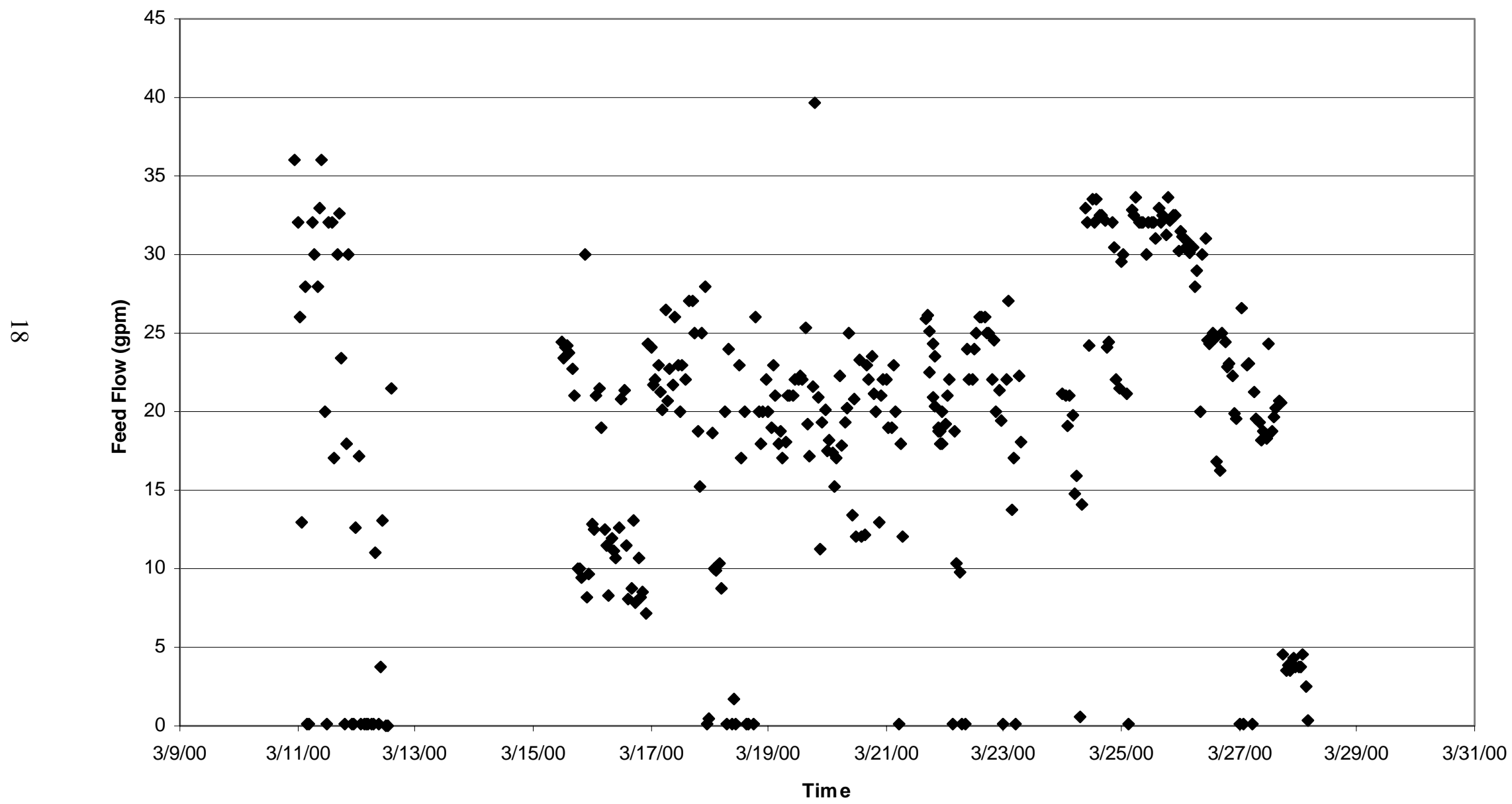

Fig. 9. Feed flow rate to the SLS system as a function of time for Run 9. 
The axial flow rate across the filter elements, which is delivered by the filter circulation pump, is presented as a function of time in Fig. 10. As can be seen, the axial flow rate across the filters was fairly constant. The step changes shown in Fig. 10 typically occurred when the pump output was changed in

the control system so that the corresponding effect on the filtrate output through the filter elements could be examined. Also, even though the feed to the SLS was very erratic (Fig. 9), the filter elements that were performing the separation were experiencing a very steady flow rate; therefore, the erratic feed flow did not affect the separation.

The transmembrane pressure, shown as a function of time in Fig. 11, was typically maintained at $\sim 8$ psig. On March 16, the transmembrane pressure was increased to $\sim 25 \mathrm{psig}$ for $\sim 24 \mathrm{~h}$ and on March 22 it was decreased to $\sim 3$ psig to determine its effect on the filtrate production rate. As can be seen from comparing Figs. 8 and 11, the filtrate production rate increased from $\sim 1$ to $\sim 3.5 \mathrm{gal} / \mathrm{min}$ when the transmembrane pressure was increased from $\sim 8$ to $\sim 25$ psig. However, the filtrate rate did not decrease when the transmembrane pressure was returned to $\sim 8 \mathrm{psig}$. Therefore, the increase in filtrate production could not be directly attributed to the increase in transmembrane pressure.

\subsection{Wastewater Triad Project Run 10}

In WTP Run 10, the feed from MVST W-26 was processed by utilizing the SLS and OTE systems in series. This run was initiated on March 29 and was completed on April 15, with 13,357 gal of supernate being processed. The solids content of the feed as a function of time is presented in Fig. 12. As can be seen, it was much more difficult to maintain the cone in MVST W-26 during the early part of Run 10 than in the previous run. A total of $\sim 72 \mathrm{~h}$ of operation was required to stabilize the cone after it had been formed. During this 72 -h period, the solids content of the feed decreased from $\sim 10 \mathrm{wt} \%$ to $\sim 0.6 \mathrm{wt} \%$. The solids content then remained below $\sim 1 \mathrm{wt} \%$ for $\sim 4$ days, and the cone began to break up, introducing more solids into the SLS feed. On April 10, the cone again seemed to stabilize and the solids content of the feed increased from $\sim 1 \mathrm{wt} \%$ to $\sim 9 \mathrm{wt} \%$ over a period of $\sim 5$ days. When the solids content reached $>9$ wt $\%$, the feed to the SLS was shut off and the solids were rinsed from the system.

The feed flow rate to the SLS system and the axial flow rate across the filters as a function of time are presented in Figs. 13 and 14, respectively, for Run 10. The results are very similar to those from Run 9; the feed flow rate was erratic, while the axial flow rate was steady except for step changes made by the operator to examine the effects on the filtrate production rate. Again, the erratic feed flow rate can be attributed to operational problems with the double-diaphragm pumps. 


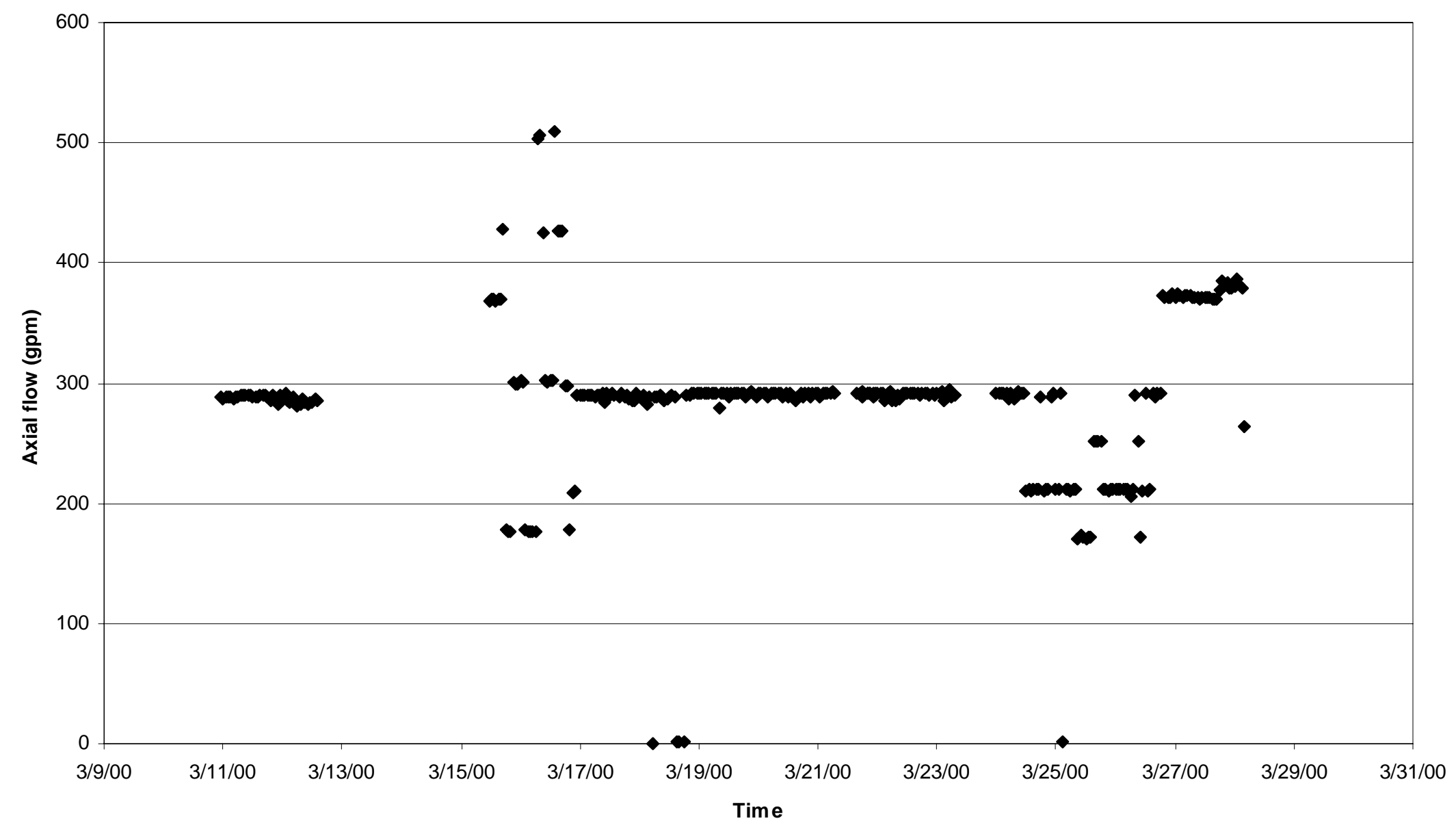

Fig. 10. Axial flow rate across the filter elements as a function of time for Run 9. 


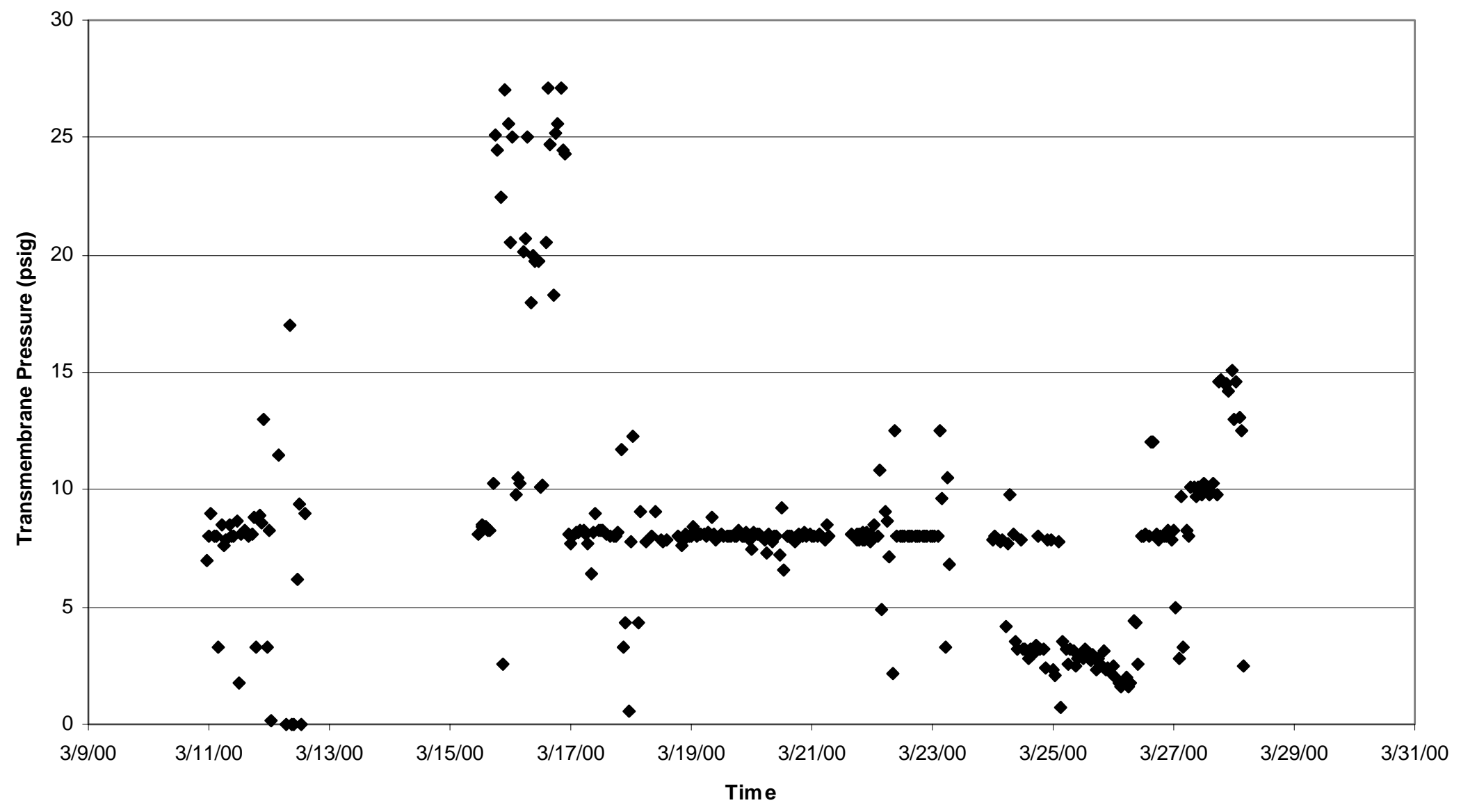

Fig. 11. Transmembrane pressure as a function of time for Run 9. 


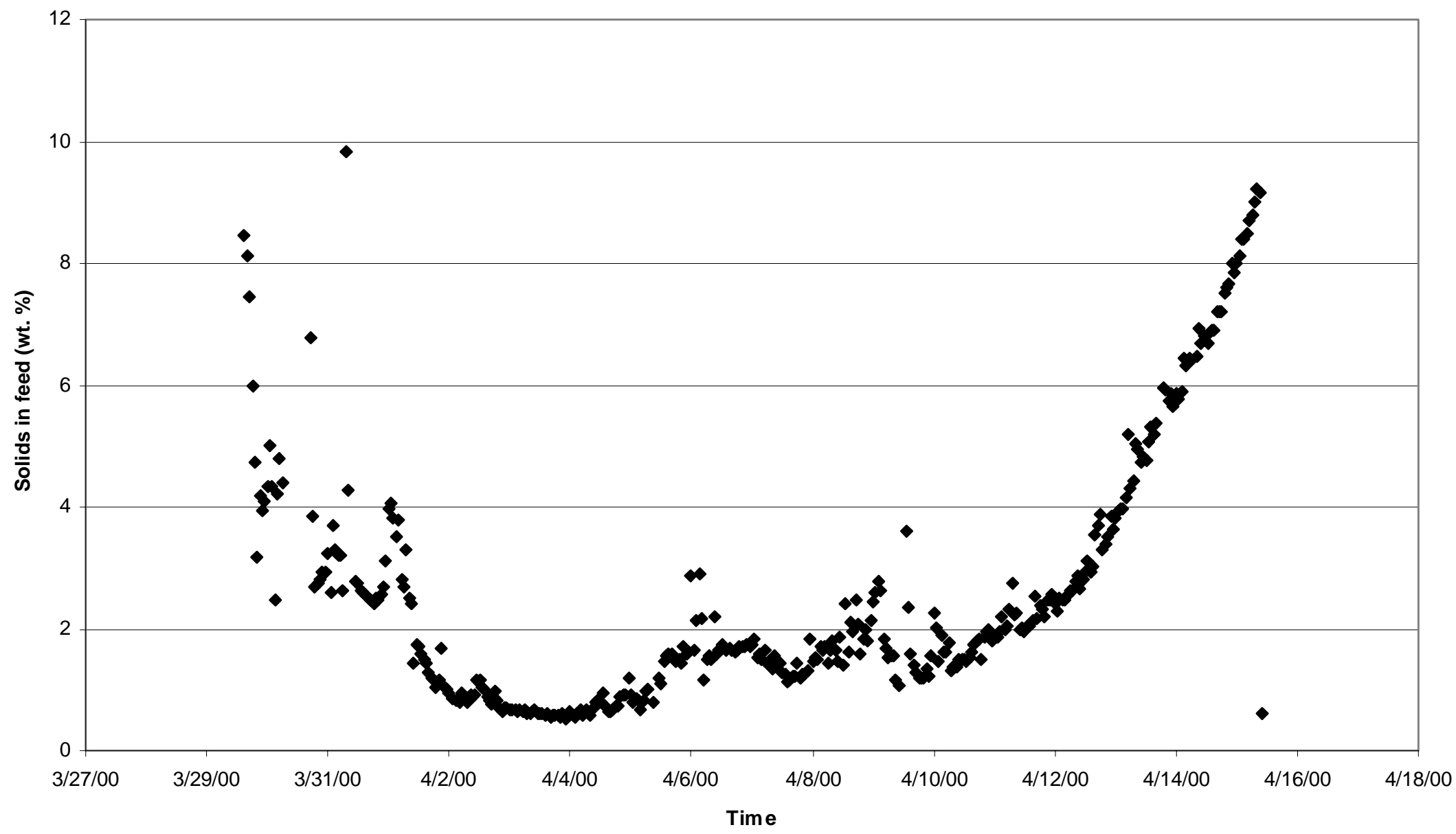

Fig. 12. Solids content of feed as a function of time for Run 10. 


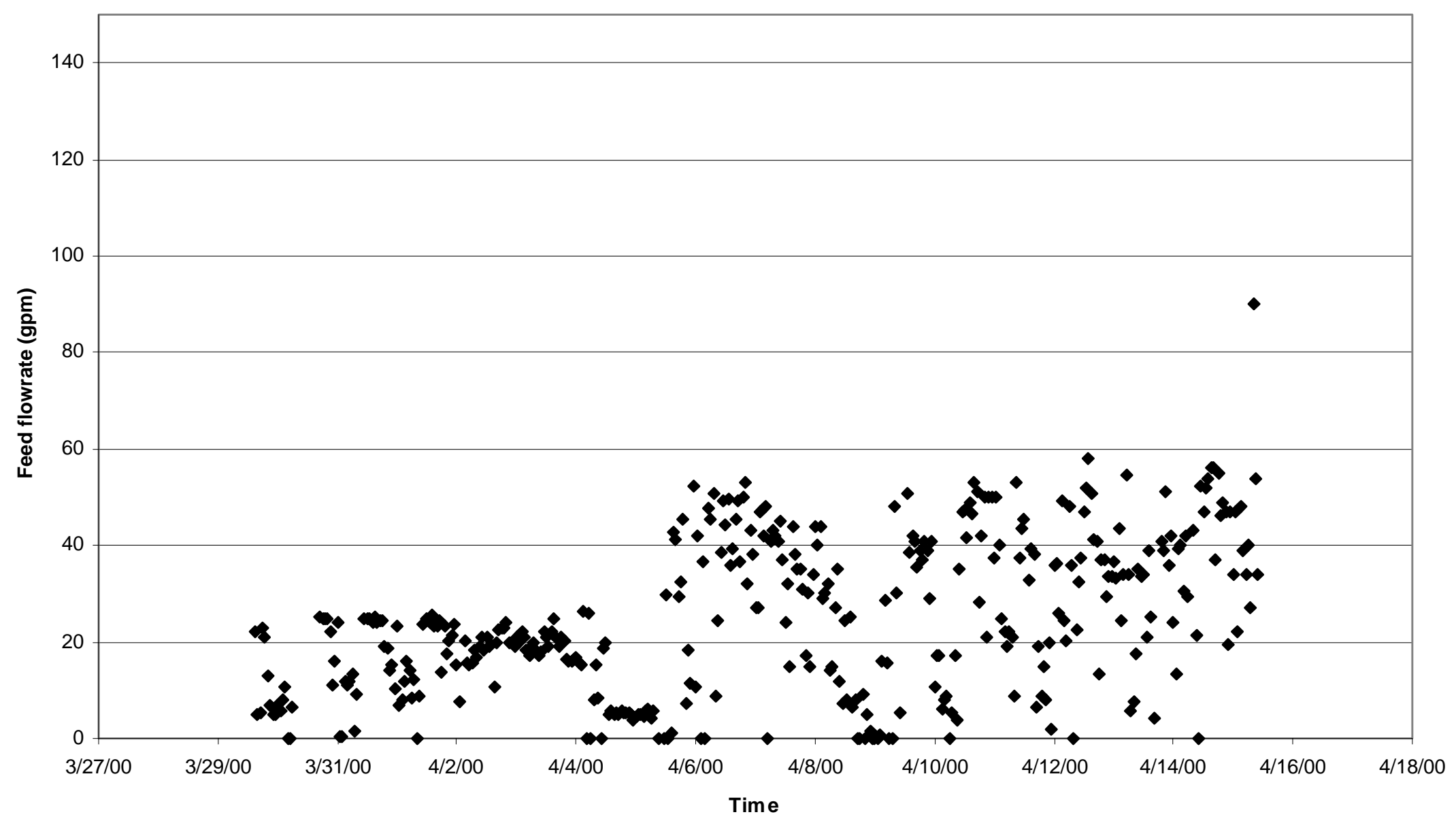

Fig. 13. Flow rate of feed to the SLS system as a function of time for Run 10. 


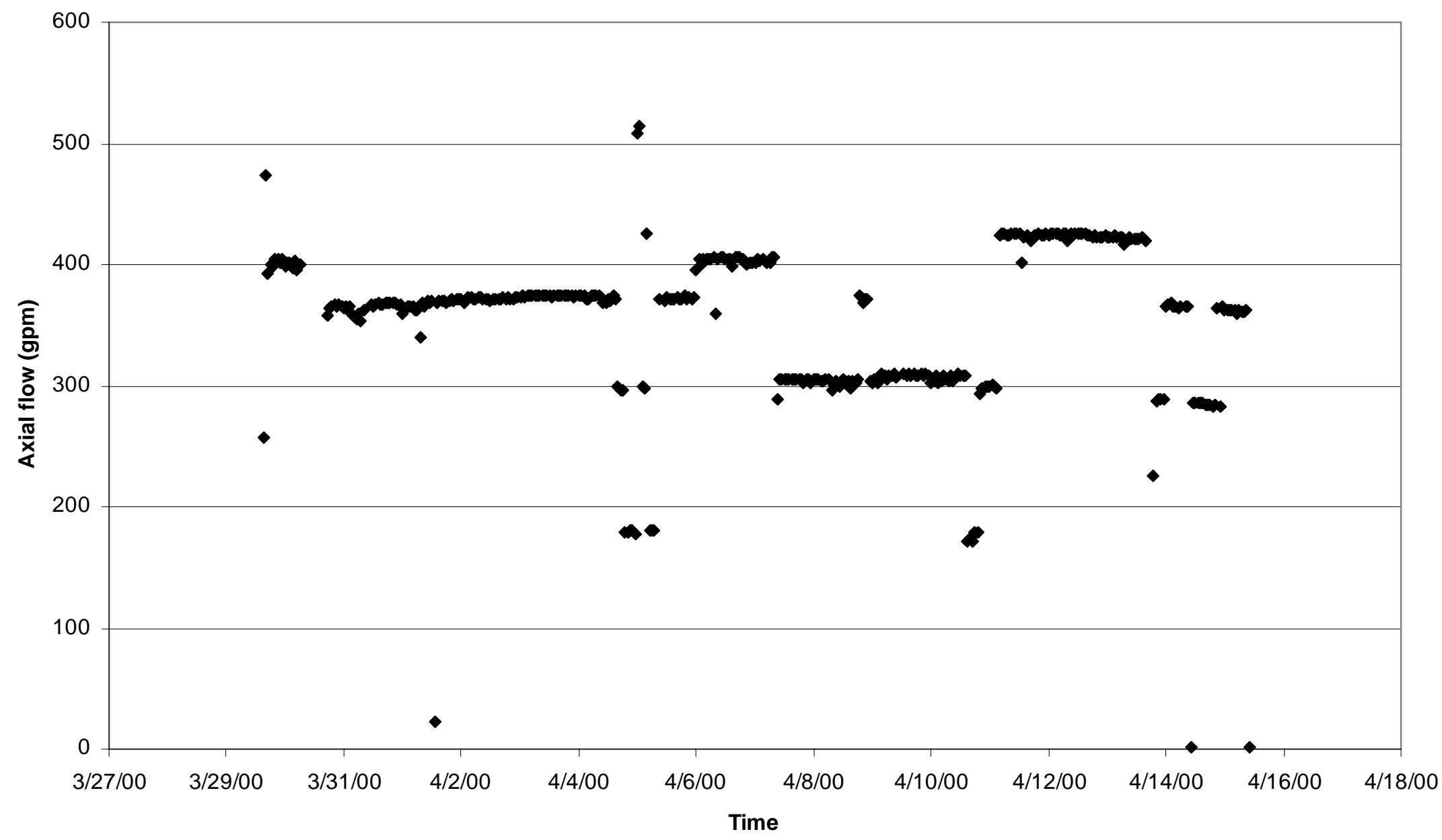

Fig. 14. Axial flow rate across filter elements as a function of time for Run 10. 
The filtrate flow rate is presented as a function of time for Run 10 in Fig. 15. As shown, the filtrate production rate typically operated in the range of $\sim 1-2 \mathrm{gal} / \mathrm{min}$ throughout the entire run. This filtrate production rate was similar to the rate observed at the end of Run 9, indicating that filtrate production may have reached a steady-state level for this system. Also, a comparison of Figs. 14 and 15 shows that changes in the axial flow had no obvious effect on the filtrate production rate.

The transmembrane pressure and the pressure drop across the filters with time are presented in Figs. 16 and 17, respectively, for Run 10. The transmembrane pressure held steady until April 4 and then became very erratic. A comparison of Figs. 13 and 16 shows that the transmembrane pressure was affected by the variability of the inlet flow rate. However, the variability in the transmembrane pressure (Fig. 16) appeared to have no negative impact on the filtrate flow rate (Fig. 15).

Figure 17, shows that the pressure drop across the filters typically varied from $\sim 4$ to $\sim 10$ psig. This range did not appear to increase as the percentage of solids in the feed increased, indicating that the axial flow across the surface of the filter was sufficient to keep the solids from building up on the surface of the filter and impeding flow through it.

\subsection{Evaluation of the Dual Coriolis Meter System}

Since treatment of underground storage tanks at DOE facilities typically involves the transfer of radioactive material, it is critically important for all transfers to be made without plugging pipelines. To reduce such risks, the relevant properties of the slurry (e.g., density, suspended solids concentration, viscosity, and particle size distribution) should be determined within acceptable limits prior to transfer. These properties should then be continuously monitored and controlled within specified limits while the transfer is in progress. One of the highest priorities is to determine the concentration of suspended solids in the slurries. During WTP Runs 9 and 10, two Coriolis meters were used simultaneously to create a suspended solids monitoring system that would provide accurate results with high precision. One Coriolis meter was used to measure the density of the slurry, while the other meter was used to measure the density of the carrier fluid (i.e., the filtrate from the cross-flow filter elements after the solids had been removed). The suspended solids concentration was then calculated from the density relationships between the slurry, the carrier fluid, and the dry solid particles. The density of the dry solids was determined by laboratory analysis and was assumed to be constant throughout the periods that grab samples were collected. Grab samples were collected and analyzed to verify the results obtained with the dual Coriolis meter system. The results showed that the concentrations of suspended solids as reported by this system tended to be slightly higher than those obtained from laboratory analyses. The standard 


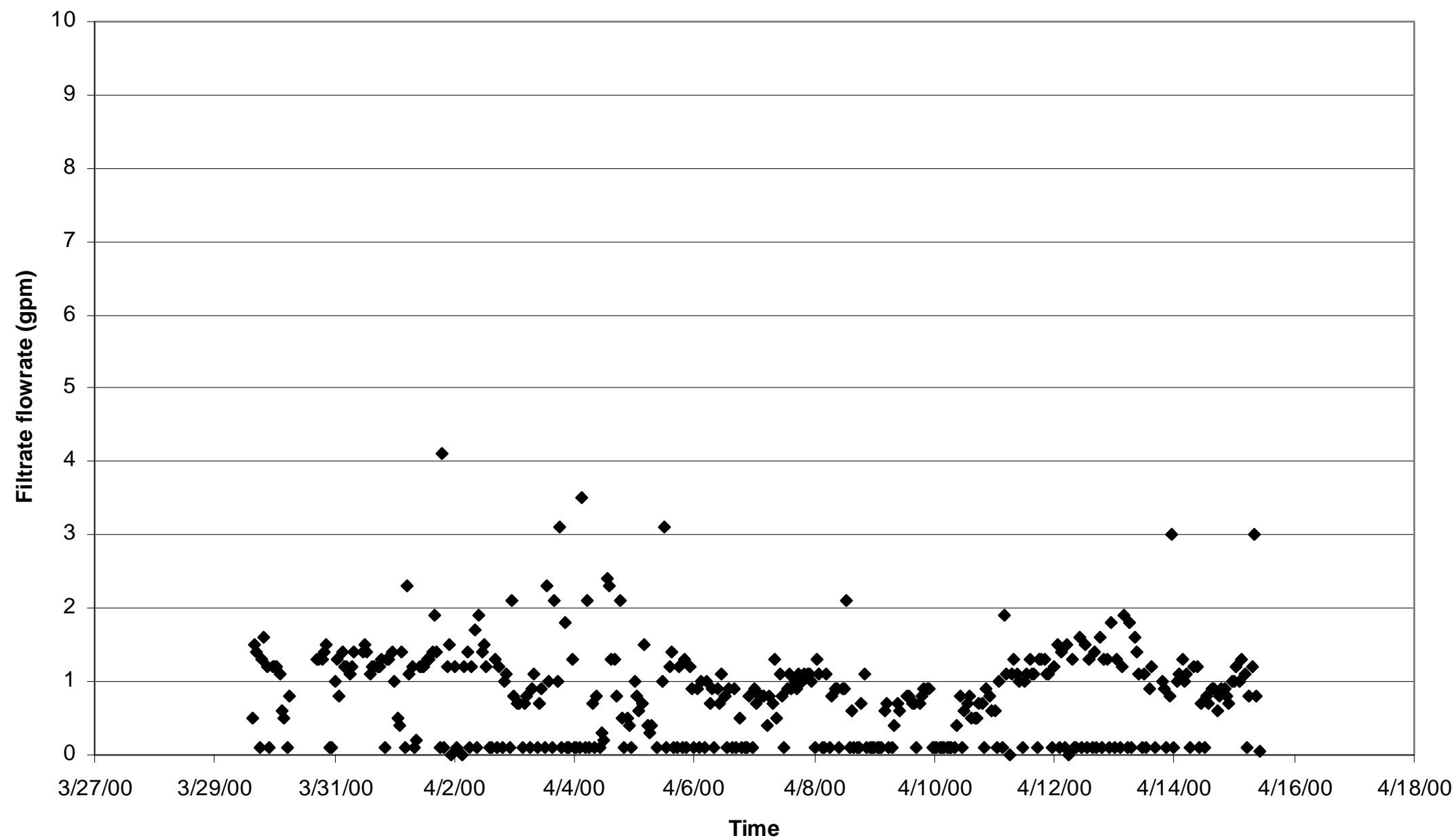

Fig. 15. Filtrate flow rate as a function of time for Run 10. 


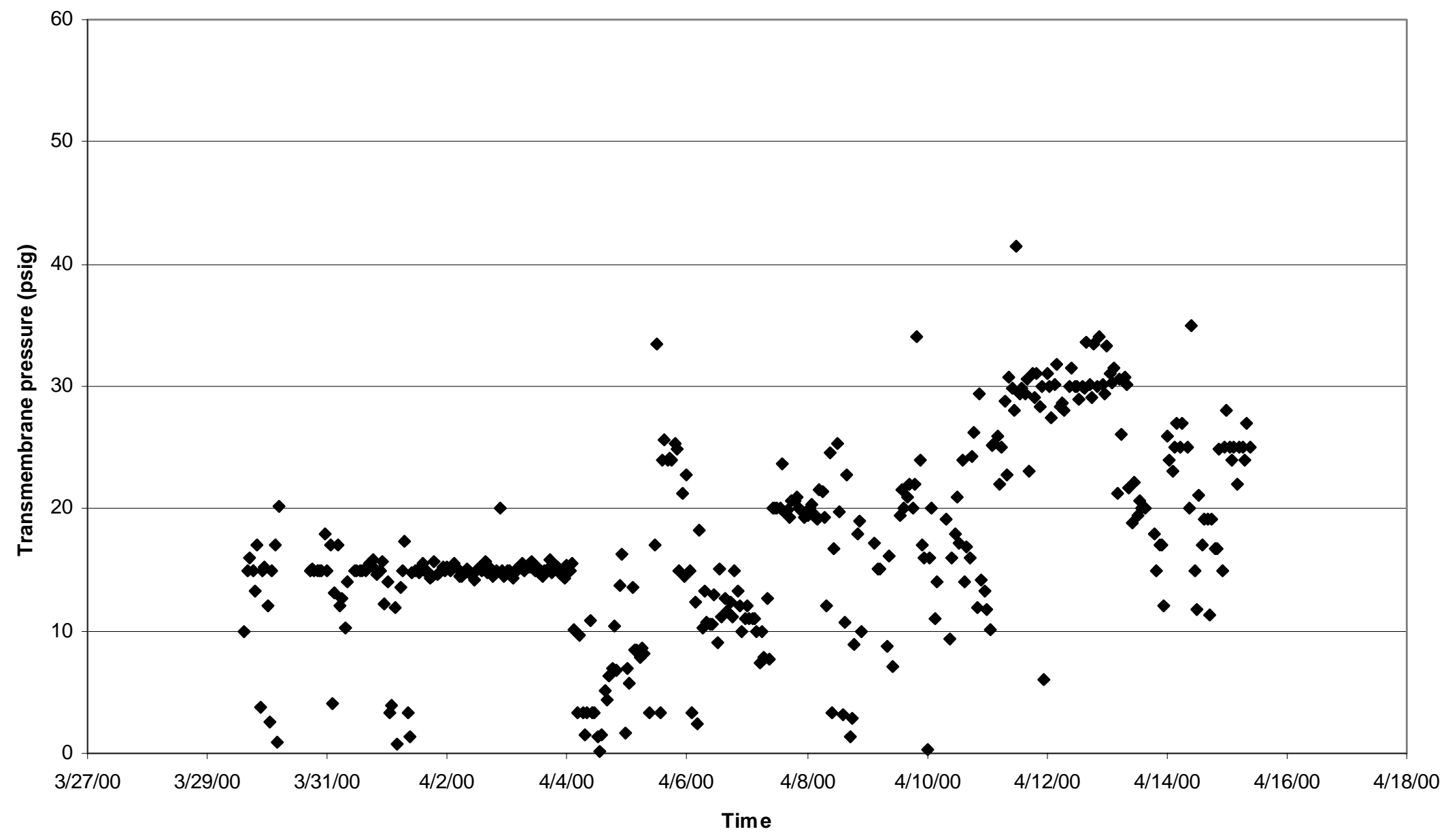

Fig. 16. Transmembrane pressure as a function of time for Run 10. 


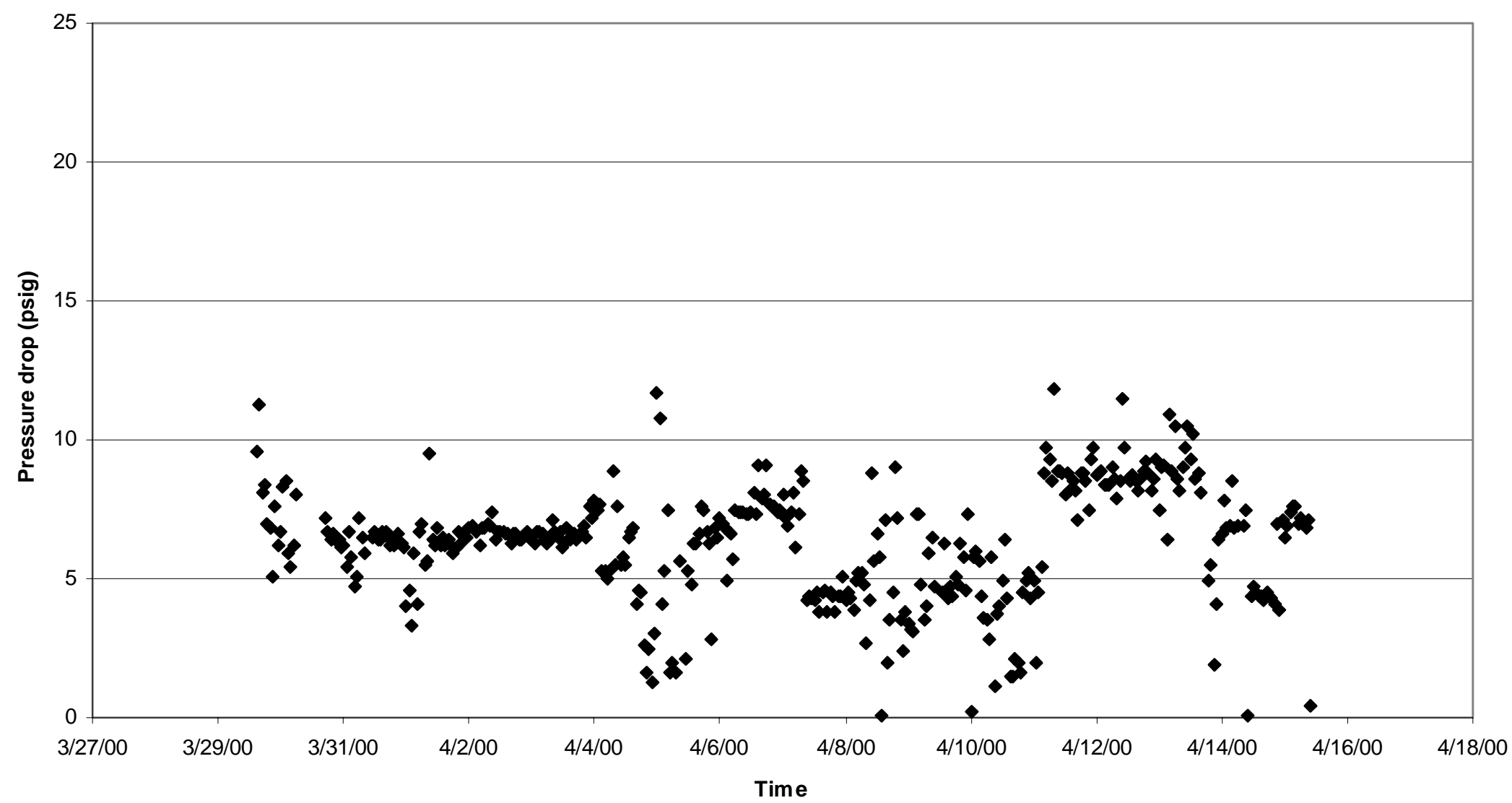

Fig. 17. Pressure drop across the filters as a function of time for Run 10. 
deviation of the suspended solids concentration determined with the dual instruments was $0.08 \%$. The precision (or repeatability) for the Coriolis meters was very good, with each meter having a standard deviation of $\leq 0.0005 \mathrm{~g} / \mathrm{mL}$ for the density. These results are quite satisfactory when one considers that the densities of the slurries were 0.01 to $0.05 \mathrm{~g} / \mathrm{mL}$ greater than those of the filtrates. A report detailing the results of the dual Coriolis meter system has been prepared by Hylton. ${ }^{6}$

\section{SUMMARY}

The Wastewater Triad Project consists of three operational units: the cesium removal (CsR) system, the out-of-tank evaporator (OTE) system, and the solid/liquid separation (SLS) system. These treatment systems are designed to reduce the volume and radioactivity of LLLW stored in the MVSTs and can be operated independently or in series in order to accomplish the treatment goals. Each of these systems is a modular, skid-mounted type that is self-contained, individually shielded, and designed to be decontaminated and removed once the project has been completed. The CsR and OTE systems are installed inside Building 7877, while the SLS system is installed adjacent to the east side of the MVST 7830 vault cover. The objective of this report is to provide a summary of the operations for the SLS system during the deployment phase in FY 2000. Operational information on the OTE and CsR systems will be provided in a report to be issued at a later date.

Two of the five runs (i.e., Runs 9 and 10) completed during FY 2000 included the SLS system. Run 9 began on March 10 and was completed on March 28, 2000. Approximately 11,911 gal of waste was processed through the SLS system during this run. The solids content of the feed initially started at $\sim 2 \mathrm{wt} \%$ and rapidly decreased to $<1 \mathrm{wt} \%$. After the cone had been stabilized, the solids content remained below $1 \mathrm{wt} \%$ for $\sim 16$ days of operation. On March 27, the solids content of the feed started to rise, increasing from $\sim 0.6 \mathrm{wt} \%$ to $\sim 3 \mathrm{wt} \%$ over a period of approximately $28 \mathrm{~h}$. The percent solids then jumped from $\sim 3 \mathrm{wt} \%$ to $\sim 22 \mathrm{wt} \%$, indicating that the cone around the suction leg in MVST W-24 had collapsed. During the early portion of Run 9 , the filtrate production rate climbed to $\sim 4-5 \mathrm{gal} / \mathrm{min}$ and operated at this rate for $\sim 8$ days before declining to a rate of $\sim 1 \mathrm{gal} / \mathrm{min}$, where it stayed for the remainder of the run ( 2 days). The $4-5 \mathrm{gal} / \mathrm{min}$ was typical of the filtrate rate during the latter stage of the SLS demonstration, which occurred earlier in FY 2000 prior to Run 9. The filtrate production rate for a cross-flow filter generally declines for a short period after startup and then reaches a steady-state production rate. The $\sim 1$-gal/min rate achieved at the close of Run 9 was adequate for the WTP because 
the CsR and OTE systems generally operate at $1 \mathrm{gal} / \mathrm{min}$; therefore, the SLS system did not become a bottleneck for the downstream processes.

Run 10 was initiated on March 29 and was completed on April 15, 2000 with 13,357 gal of supernate being processed through the SLS system. During this run, $\sim 72 \mathrm{~h}$ of operation was required to stabilize the cone in MVST W-26 after the cone had been formed. During the $72 \mathrm{~h}$ period, the solids content of the feed to the SLS system decreased from $\sim 10 \mathrm{wt} \%$ to $\sim 0.6 \mathrm{wt} \%$. The percentage solids in the feed remained below $\sim 1$ wt $\%$ for $\sim 4$ days; then the cone began to break up, introducing more solids into the SLS feed. On April 10, the cone again seemed to stabilize and the solids content of the feed increased from $\sim 1$ wt $\%$ to $\sim 9$ wt $\%$ over a period of $\sim 5$ days. When the solids content reached $>9$ wt $\%$, the feed to the SLS system was shut off, the solids were ri/nsed from the system, and Run 10 was terminated. The feed flow rate to the SLS and the axial flow rate across the filters during Run 10 were very similar to those in Run 9; the feed flow rate was erratic, but the axial flow rate was steady except for step changes made by the operator to examine the effects on the filtrate production rate. The filtrate production rate typically operated in the range of $\sim 1-2$ gal/min throughout Run 10 . This filtrate production rate was typical of the rate observed at the end of Run 9, indicating that filtrate production may have reached a steady-state level for this system. Again, the rate of $\sim 1 \mathrm{gal} / \mathrm{min}$ did not become a bottleneck for the downstream processes because the OTE and CsR systems were designed to operate at this level.

During WTP Runs 9 and 10, two Coriolis meters were used simultaneously to create a suspended solids monitoring system that would provide accurate results with high precision. One Coriolis meter was used to measure the density of the slurry, while the other meter was used to measure the density of the carrier fluid (i.e., the filtrate from the cross-flow filter elements after the solids had been removed). The suspended solids concentration was then calculated from the density relationships between the slurry, the carrier fluid, and the dry solid particles. The density of the dry solids was determined by laboratory analysis and was assumed to be constant throughout the periods that grab samples were collected. Grab samples were collected and analyzed to verify the results obtained with this system. The results showed that the concentrations of suspended solids as reported by this system tended to be slightly higher than those obtained from laboratory analyses. The standard deviation of the suspended solids concentration determined with the dual instruments was $0.08 \%$. The precision (or repeatability) for the Coriolis meters was very good; each meter had a standard deviation of $\leq 0.0005 \mathrm{~g} / \mathrm{mL}$ for the density. Such results are quite satisfactory when one considers that the densities of the slurries were 0.01 to $0.05 \mathrm{~g} / \mathrm{mL}$ greater than those of the filtrates. 


\section{REFERENCES}

1. A. J. Lucero et al., Out-of-Tank Evaporator Demonstration: Final Report, ORNL/TM-13501, Oak Ridge National Laboratory, Oak Ridge, Tennessee, February 1998.

2. J. F. Walker et al., Cesium Removal Demonstration Utilizing Crystalline Silicotitanate Sorbent for Processing Melton Valley Storage Tank Supernate: Final Report, Oak Ridge National Laboratory, Oak Ridge, Tennessee, March 1998.

3. T. E. Kent, J. H. Wilson, and J. R. Farmer, Development and Deployment of a Full-Scale CrossFlow Filtration System for Treatment of Liquid Low-Level Waste at Oak Ridge National Laboratory, ORNL/TM-2000/27, Oak Ridge National Laboratory, Oak Ridge, Tennessee, 2000.

4. E'S-WTP-001, E'S-WTP-002, E'S-WTP-003, E'S-CSR-001, E'S-OTE-001, and E'S-SLS-001, Wastewater Triad Project Procedures, Oak Ridge National Laboratory, Oak Ridge, Tennessee.

5. E'S-WTP-01, E'S Document Control Procedure, Oak Ridge National Laboratory, Oak Ridge, Tennessee.

6. T. D. Hylton, An Evaluation of a Dual Coriolis Meter System for In-Line Monitoring of Suspended Solids Concentrations in Radioactive Slurries, ORNL/TM-2000/184, Oak Ridge National Laboratory, Oak Ridge, Tennessee, September 2000. 
ORNL/TM-2000/186

\section{INTERNAL DISTRIBUTION}

1. T. D. Hylton

2. R. T. Jubin

3. C. M. Kendrick

4. T. E. Kent

5. C. P. McGinnis

6. L. E. McNeese

7. S. M. Robinson
8. S. D. Van Hoesen

9-23. J. F. Walker, Jr.

24. Central Research Library

25. ORNL Laboratory Records

26. ORNL Laboratory Records-OSTI

27. ORNL Laboratory Records-RC

28. CTD/ADM DMC

\section{EXTERNAL DISTRIBUTION}

29. R. W. Allen, Pacific Northwest National Laboratory, P.O. Box 999, MS-K9-69, Richland, WA 99352

30. T. M. Brouns, Pacific Northwest National Laboratory, P.O. Box 999, MS-K9-69, Richland, WA 99352

31. W. Brown, Fernald, 7400 Willey Road, MS-67, Cincinnati, OH 45030

32. L. D. Bustard, Sandia National Laboratory, P.O. Box 5800, MS-728, Albuquerque, MN 87185-5800

33. J. T. Carter, Westinghouse Savannah River Company, Bldg. 704-3N, Room S151, Aiken, SC 29808

34. B. A. Carteret, Pacific Northwest National Laboratory, P.O. Box 999, MS-K9-91, Richland, WA 99352

35. S. D. Fink, Westinghouse Savannah River Company, Bldg. 773-A, Room B-112, Aiken, SC 29808

36. K. D. Gerdes, DOE-OST, EM-54, 19901 Germantown Road, Germantown, MD 20874

37. R. L. Gilchrist, Pacific Northwest National Laboratory, P.O. Box 999, MS-K9-91, Richland, WA 99352

38. D. D. Green, U.S. Department of Energy, Oak Ridge Operations Office, P.O. Box 2001, Oak Ridge, TN 37830-8620

39. R .S. Herbst, Idaho National Engineering and Environmental Laboratory, P.O. Box 1625, Idaho Falls, ID 83415-5218

40. E. W. Holtzscheiter, Westinghouse Savannah River Company, Savannah River Technology Center, Bldg. 773-A, Room A229, Aiken, SC 29802

41. J. Jewett, Numatec Hanford Corporation, P.O. Box 1970, Richland, WA 99352

42. R. A. Kirkbride, Numatec Hanford Corporation, P.O. Box 1970, MS-H5-27, Richland, WA 99352

43. D. E. Kurath, Pacific Northwest National Laboratory, P.O. Box 999, MS-P7-28, Richland, WA 99352

44. K. A. Lockie, DOE/INEEL, P.O. Box 1625, Bldg. ID-S, Room 56, Idaho Falls, ID 834155218 
45. N. R. Mann, Idaho National Engineering and Environmental Laboratory, P.O. Box 1625, Idaho Falls, ID 83415-5218

46. D. J. McCabe, Westinghouse Savannah River Company, Road 1, Bldg. 773-42A, Room 152, Aiken, SC 29808

47. J. P. Morin, Westinghouse Savannah River Company, Savannah River Technology Center, Bldg. 703-H, Aiken, SC 29808

48. J. A. Murphy, Idaho National Engineering and Environmental Laboratory, Bldg. WCB, MS-3404, Idaho Falls, ID 83415-3404

49. C. A. Musick, Idaho National Engineering and Environmental Laboratory, P.O. Box 1625, Idaho Falls, ID 83415-5218

50. C. A. Nash, Westinghouse Savannah River Company, Road 1, Bldg. 773-42A, Aiken, SC 29808

51. J. R. Noble-Dial, U.S. Department of Energy, Oak Ridge Operations Office, P.O. Box 2001, Oak Ridge, TN 37830-8620

52. A. L. Olson, Idaho National Engineering and Environmental Laboratory, P.O. Box 1625, Idaho Falls, ID 83415-5218

53. D. R. Peterman, Idaho National Engineering and Environmental Laboratory, P.O. Box 1625, Idaho Falls, ID 83415-5218

54. T. P. Pietrok, U.S. Department of Energy, Richland Operations Office, P.O. Box 550, MSK8-50, Richland, WA 99352

55. M. R. Poirier, Westinghouse Savannah River Company, Road 1, Bldg. 773-42A, Aiken, SC 29808

56. J. A. Rindfleisch, Idaho National Engineering and Environmental Laboratory, P.O. Box 1625, Idaho Falls, ID 83415-5218

57. W. L. Tamosaitis, Westinghouse Savannah River Company, Bldg. 773-A, Room A-231, Aiken, SC 29808

58. M. T. Terry, Los Alamos National Laboratory, P.O. Box 1663, MS-K557, Los Alamos, NM 87545

59. T. R. Thomas, Idaho National Engineering and Environmental Laboratory, P.O. Box 1625, Bldg. EROB, Idaho Falls, ID 83415-3760

60. T. A. Todd, Idaho National Engineering and Environmental Laboratory, P.O. Box 1625, Idaho Falls, ID 83415-5218

61. J. H. Valentine, Idaho National Engineering and Environmental Laboratory, P.O. Box 1625, Bldg. WCB, MS-3211, Idaho Falls, ID 83415-5218

62. W. B. Van-Pelt, Westinghouse Savannah River Company, Road 1, Bldg. 773-42A, Aiken, SC 29808

63. J. H. Westsik, Pacific Northwest National Laboratory, P.O. Box 999, MS-K9-9122, Richland, WA 99352

64. B. J. Williams, Pacific Northwest National Laboratory, P.O. Box 999, MS-K9-69, Richland, WA 99352 